\title{
The Multiple Mediators of Early Differences in Academic Abilities by Parental Financial Resources in Germany
}

\author{
Jascha Dräger $^{1^{*}}$ and Klaus Pforr ${ }^{1}$ \\ ${ }^{1}$ GESIS - Leibniz Institute for the Social Sciences
}

*Corresponding author: jascha.draeger@gesis.org, GESIS - Leibniz Institute for the Social Sciences, Department Monitoring Society and Social Change, P.O. Box 1221 55, 68072 Mannheim, Germany

\section{Acknowledgements}

This paper uses data from the National Educational Panel Study (NEPS): Starting Cohort Newborns, doi:10.5157/NEPS:SC1:7.0.0. From 2008 to 2013, NEPS data was collected as part of the Framework Program for the Promotion of Empirical Educational Research funded by the German Federal Ministry of Education and Research (BMBF). As of 2014, NEPS is carried out by the Leibniz Institute for Educational Trajectories (LIfBi) at the University of Bamberg in cooperation with a nationwide network.

We are grateful for comments made by the participants of the DGS conference in Berlin, the SLLS conference in Potsdam, and workshop participants in Leipzig and Venice. Furthermore, we would like to thank Michael Kühhirt, Nora Müller, Reinhard Pollak, Alejandra Rodríguez Sánchez, and Øyvind Wiborg for feedback on earlier drafts.

\section{Declaration of Interest Statement}

This work was supported by the "German Research Foundation" (DFG) under Grant No. 403547843. We have no known conflicts of interest to disclose. 


\section{The Multiple Mediators of Early Differences in Academic Abilities by Parental Financial Resources in Germany}

This paper examines the mediators of differences in academic abilities by parental income and wealth among pre-schoolers in Germany. Families' investment, parental stress and parenting, neighbourhood effects, and parents' educational norms and aspirations are considered as mediators. Unlike most existing studies, we explicitly consider the interdependence of these mediators and, therefore, apply sequential joint mediation analysis. We find that children in income-poor households score up to 0.34 standard deviations lower and children in households with a negative net worth up to 0.24 standard deviations lower in tests of academic ability, even when controlling for a comprehensive set of other familial characteristics. All mediators together explain on average $47 \%$ of the differences by income, but only $17 \%$ of the wealth differences. Parental investment is the most important mediator, followed by neighbourhood effects. Parental Stress, mother-child interaction quality, and educational norms and aspirations seem to be less relevant as mediators.

Keywords: Economic Resources, Family Investment Model, Family Stress Model, Mediation Analysis, Wealth Inequality 


\section{Introduction}

There is strong evidence that children of parents with high socioeconomic status have higher cognitive skills, perform better in school, and achieve higher educational degrees. The social stratification of academic abilities occurs even before children enter school, and it is almost never fully redressed (e.g., Feinstein 2003; T. Linberg et al. 2019; Skopek and Passaretta 2021). These early differences in academic abilities have crucial consequences for children's further cognitive development and long-term consequences for their educational and occupational career.

Families' financial resources play an important role in the early social stratification of academic abilities. Children in families at the top of the income distribution score more than one standard deviation higher in standardised test scores in the US compared to children in families at the bottom of the income distribution (Reardon 2011). These differences get smaller when adjusting for other parental characteristics, or when applying fixed-effects or instrumental variables approaches, but important disparities remain (e.g., Dahl and Lochner 2012; Duncan and Murnane 2011). Yet, income alone is not sufficient to capture the financial resources of families. Recent research shows that parental wealth contributes to differences in academic abilities, even when controlling for income and other familial characteristics. In the US, children in wealthy households were found to display substantially higher cognitive abilities and academic achievement than their less wealthy peers (Diemer, Marchand, and Mistry 2020; Friedline, Masa, and Chowa 2015; Orr 2003; Williams Shanks 2007; Yeung and Conley 2008). However, the size of the wealth effect seems to depend on the domain of academic achievement (Elliott, Destin, and Friedline 2011). For Sweden (Hällsten and Pfeffer 2017) and for Norway (Wiborg 2017) substantial differences in adolescents' grade point average by parental wealth were found. These differences in cognitive abilities and academic achievement later lead to lower educational attainment (Diemer, Marchand, and Mistry 2020; 
Hällsten and Pfeffer 2017; Karagiannaki 2017). In contrast to these findings, for the UK, Moulton et al. (2021) found only small differences in cognitive abilities of 11-year-old children by parental wealth, once they adjusted for parents' permanent income.

To fully understand and potentially reduce these disparities, knowledge regarding their underlying mechanisms is needed. Important progress has already been made analysing the underlying mechanisms of the differences in academic ability by parental income. Substantial proportions of these academic ability-income differences can be explained by parents' investment in children (i.e., the Family Investment Model; Becker and Tomes 1986), parental stress and parenting behaviour (i.e., the Family Stress Model; Conger and Conger 2002), and neighbourhood differences (Leventhal and Brooks-Gunn 2000).

Despite this progress, crucial research gaps remain three of which we address in this paper. First, we evaluate whether academic ability differences by parental wealth are caused by the same mechanisms as differences by income. Only a few studies have evaluated the underlying mechanisms of wealth disparities in academic abilities (Diemer, Marchand, and Mistry 2020; Orr 2003), even though they are likely caused by other mechanisms than income disparities (Hällsten and Pfeffer 2017).

Second, we test the mediators of academic ability differences in a different institutional context, namely Germany. Most of the theories aiming to explain these disparities are derived from and evaluated in the US context. Yet, it is questionable whether they can be generalised to other countries. Germany provides an interesting case study for this research question. On the one hand, we could expect less pronounced differences by financial resources due to the more generous welfare state and the fact that public resources are less dependent on the neighbourhood one lives in (Pfeffer and Hällsten 2012). On the other hand, educational attainment is strongly stratified and the German system of early ability tracking in school may make early investment more important. Few studies that have explicitly examined 
the impact of parents' financial resources on early academic abilities in Germany. These studies found that there are disadvantages regarding the academic abilities of children living in income-poor households or households with negative or zero net worth (Biedinger 2011; Schulz et al. 2017). These differences later translate into a lower educational attainment (Dräger 2021; Dräger and Müller 2020; Schneider 2004).

Third and most importantly, we take into account that the different mediators of academic ability differences by parents' financial resources are likely not independent but affect each other causally (e.g., Coley et al. 2021; Layte 2017). Since the different explanations for the disparities come from different disciplines, they are often tested separately, or in comparison to each other. However, as pointed out by the development in causal mediation analysis in the last decade, analysing causally related mediators as if they were independent gives biased results, because mediators early in the causal chain serve as confounders for the effect of other mediators on the outcome. Moreover, common approaches for mediation analysis, like the difference method (Baron and Kenny 1986), assume that there are no interactions between exposure and mediators or among the mediators. Here, we apply sequential joint mediation analysis to overcome these issues (VanderWeele and Vansteelandt 2014; VanderWeele, Vansteelandt, and Robins 2014).

\section{Background}

There exist several explanations for the association between parents' financial resources and children's academic abilities. We consider the family investment model, the family stress model, the neighbourhood, and educational norms and aspirations.

\section{Family Investment Model}

The family investment model (FIM) proposes that parents invest their resources (time and money) in the development of their children to increase their children's human capital 
(Becker and Tomes 1986). These investments increase children's academic abilities. Since families with more financial resources are less constrained in their investments, their children will have higher academic abilities than children in families with fewer financial resources. Investment in several components enhances the cognitive development of children and partially mediates the differences in academic abilities by parents' financial resources: These components include children's basic needs (e.g., housing and food), learning materials, and stimulating activities and services, including organised leisure activities and cultural activities. Empirical studies have identified parental investment as the main mediator of income differences in children's cognitive development for the US (e.g., Davis-Kean 2005; Guo and Harris 2000; Yeung, Linver, and BrooksGunn 2002) but also for the UK (Layte 2017; Violato et al. 2011). Similarly, differences by parental wealth are partially mediated by parental investment (Orr 2003).

For Germany, we expect smaller differences in parental investment as households are less likely to suffer from economic hardship because of the more generous welfare state. The few empirical studies on financial resources and investment in Germany have mixed results: Income was found to be associated with more activities and materials promoting literacy, but not for activities and materials promoting numeracy (Kluczniok et al. 2013). Other studies found that higher income is associated with more participation in informal activities like early music education, but not with the frequency of visiting places of cultural learning like concerts or theatres (Mudiappa and Kluczniok 2015).

\section{Family Stress Model}

The family stress model (FSM) proposes that economic hardship causes stress for families, thereby disrupts children's social-emotional and cognitive development. In the first step, economic hardship puts families under economic pressure. This increases parents' emotional stress and the probability of behavioural problems, which may result in feelings of depression 
and increased conflict between parents. Parental stress leads to less parental warmth, inconsistency in parenting, and less involved parenting. Ultimately, this reduction of interaction quality inhibits cognitive development and causes behavioural problems in children (Conger and Conger 2002).

Existing research usually finds that differences in academic abilities by socioeconomic background are mostly mediated through parental investment, while differences in socio-emotional behaviour are mostly mediated through parenting behaviour (Gershoff et al. 2007). However, several studies also found that parental stress and parenting behaviour affect children's cognitive development (e.g., Iruka, LaForett, and Odom 2012; Kiernan and Mensah 2011; Layte 2017; Nievar et al. 2014; Violato et al. 2011). Parental wealth may be particularly important to consider for this process in addition to parental income because debts seem to have a substantial negative effect on psychological distress (Brown, Taylor, and Wheatley Price 2005; Dunn and Mirzaie 2016), while assets create a buffer and reduce stress (Rothwell and Han 2010).

For Germany, research on the mediating role of parental stress and parenting is rare and results are inconsistent. Weinert, Attig, and Rossbach (2017) find a negative effect of income-poverty on mother-child interaction quality. Conversely, Attig and Weinert (2018) find no effect of income on mothers' interaction behaviour with toddlers. Walper and Grgic (2013) find only a negative effect of poverty on activities related to education, but not for interaction quality.

\section{Neighbourhood}

Parents with sufficient financial resources can afford to reside in or relocate to neighbourhoods that are better suited to foster their children's development (Owens 2018). On the one hand, the infrastructure and composition of a neighbourhood affect children's cognitive development directly: Children will develop better when there are high-quality 
public facilities available, when they play with other children with high cognitive abilities (Justice et al. 2011), and when they are not exposed to noise and air pollution (Evans 2006). On the other hand, the neighbourhood affects children's development indirectly by affecting parents: Parents will be more stressed when they are exposed to the threat of crime or when the neighbourhood provides them with few opportunities for recreation (Leventhal and Brooks-Gunn 2000) and will be more likely to invest in high-quality childcare, activities, and services that foster cognitive development when these are close by.

For Germany, recent research shows that families with a high socioeconomic status move to less deprived neighbourhoods when the nearby elementary schools are deemed unsuitable (Oeltjen and Windzio 2019). However, we assume neighbourhood effects to be smaller in Germany because the financial situation of a neighbourhood is less dependent on the financial resources of its residents than in the US.

\section{Educational Norms and Aspirations}

Lastly, some existing studies claim that educational norms and aspirations mediate the effect of parents' financial resources, particularly of parents' wealth. Wealth may create a sense of educational entitlement, leading wealthy families to promote pro-educational norms among their children and to have higher educational aspirations for them (Conley 2001). This can be partially attributed to families trying to secure their wealth advantage throughout generations through (higher) education, and partially to wealth enabling families to invest more in the future in general (Zhan and Sherraden 2011). To conform to these educational norms and high aspirations, children have to perform well in school (Hällsten and Pfeffer 2017), which will be easier if children already have high academic abilities before entering school. In consequence, it can be expected that parents with pro-educational norms and high aspirations will invest more resources and time in their child. Diemer, Marchand, and Mistry (2020) found that 
parental expectations mediate more than half of the wealth differences in the achievement test scores of 6 to 12-year-old children in the US.

\section{Interdependencies between Mediators}

The current state of research often considers the aforementioned mediators as being separate and independent causal pathways between parents' financial resources and children's academic abilities. However, as already noted, we assume that investment, stress, parent-child interaction quality, norms and aspirations, and neighbourhood affect each other.

The neighbourhood where a family lives defines the context for other processes that affect children's development (Williams Shanks and Robinson 2013). First, the neighbourhood affects parents' stress. Parents will be more stressed when they are exposed to the threat of crime or when the neighbourhood provides them with few recreational opportunities. Second, parents might to a lesser degree abide by pro-educational norms, if their peers in the neighbourhood value education negatively. Finally, the neighbourhood may constrain investments: Even if parents have the required financial resources for services that foster cognitive development, they cannot invest in them without ready access to these services (Leventhal and Brooks-Gunn 2000).

Secondly, parents' educational norms affect their parenting behaviour and investment. We assume that parents with high educational aspirations and a positive attitude towards education will try to implement these attitudes by using parenting styles that foster cognitive development (Davis-Kean 2005) and will be more willing to invest or undertake joint activities with their children (Kim et al. 2015).

Lastly, parental stress affects family investment. Parents with high levels of stress will invest less in their children (Gershoff et al. 2007).

These expected effects among the mediators are presented in Figure 1. Solid arrows show the effects as they are expected in the current literature, while dotted arrows show the 
potential effects between the different mediators that are yet to be examined in detail. The described interdependencies among the mediators result in a chain of mediators, with the neighbourhood as the first mediator and parents' investment as the last mediator. This chain of mediators will be used for the mediation analysis.

Although our structural model is comprehensive, there may be additional paths that we did not consider. For instance, parents with high educational aspirations might be more likely to move to neighbourhoods that provide higher school quality and a better environment for cognitive development (Kim et al. 2005). Our model cannot account for these alternative paths.

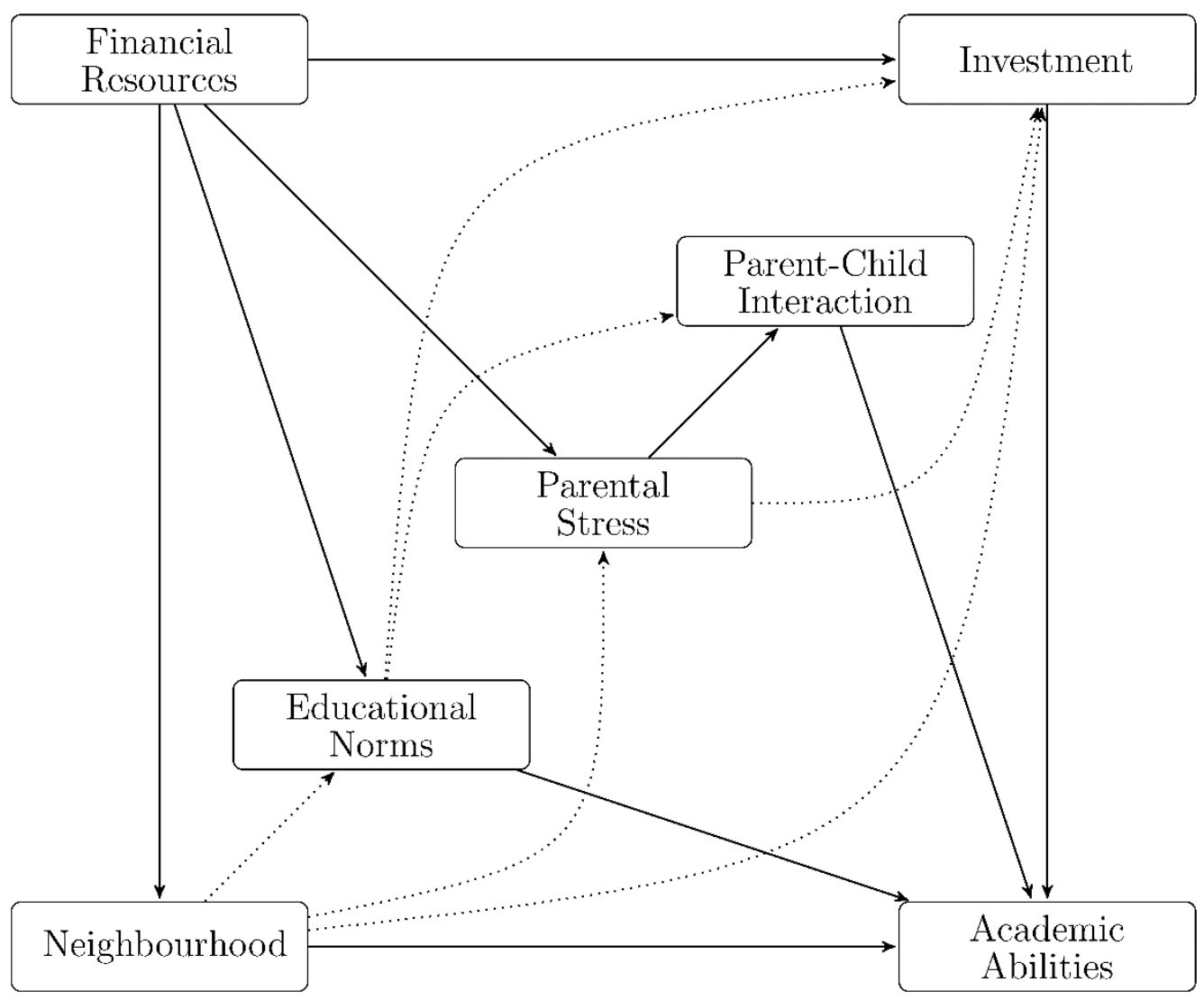

Figure 1. Theoretical path model with interdependent mediators. 


\section{Methods}

\section{Data}

For our analysis, we use data from the newborn cohort of the German National Educational Panels Study (hereafter NEPS; Blossfeld, Roßbach, and von Maurice 2011). The target population of this cohort sample were children born in Germany between February and June 2012. The data contains information about parents' socio-demographic characteristics and multiple standardised competency tests for children. Most importantly it has rich data on all potential mediators of the effect of parents' socio-economic characteristics and children's academic abilities. At the time of the most recent panel wave (2018, wave seven), the children were six years old. For our analysis, we use all children that had participated in at least one of the competency tests in waves five, six or seven. This leaves us with an analysis sample of 2,377 children out of the initial sample of 3,481 children.

We use the weighting factors offered by the NEPS to account for selective participation in the first wave of the survey and multiply these weights with the inverse of the probability to be included in the analysis sample to account for selective panel attrition. For the estimation of the probability of attrition, we use a categorisation tree (Hastie, Tibshirani, and Friedman 2009; Hayes et al. 2015) on the same variables that were used by the NEPS to estimate weights.

We generate multiple imputations for missing values in parental financial resources, mediators, control variables, and test scores for children with at least one observed test score. We create 50 imputed data sets using categorisation and regression trees (Burgette and Reiter 2010). 


\section{Academic Abilities}

We use the results of all four standardised competency tests that were assessed in the fifth, sixth, and seventh wave of NEPS. We use four different measures of children's academic abilities, assessing their competencies in math, science, and verbal ability, because the effect of parents' financial resources may depend on the domain (Elliott, Destin, and Friedline 2011). For math abilities (measured in wave five, when children were four years old and sixth wave, when they were six years old) and scientific abilities (measured in wave six when children were five years old), we use the weighted maximum likelihood estimates provided by NEPS, which were derived from performances in a standardised test with 20 tasks (Hahn et al. 2013; Peterson and Gerken 2018). Verbal ability is measured in the sixth wave by children's scores in the German adaptation of the Peabody Picture Vocabulary Test (PPVT).

\section{Financial Resources: Wealth}

Parents participating in NEPS are asked to estimate the value of all real estate and financial assets of their household and then to estimate the value of their debts and liabilities. Parental wealth was measured in the third wave when children were two years old. In line with existing research, we use parents' net worth (assets minus debts) as a measure of wealth. In our sample, net worth ranges from -400k EUR to 10m EUR and is with a mean of 310k EUR and a median of 50k EUR strongly right-skewed (see appendix A). We categorise net worth into five categories to capture potential non-linear effects:

(1) Negative net worth / 1. Quintile [-400k EUR; 0 EUR),

(2) 2. Quintile [0 EUR; 20k EUR),

(3) 3. Quintile [20k EUR; 100k EUR),

(4) 4. Quintile [100k EUR; 210k EUR),

(5) 5. Quintile [210k EUR; 10m EUR]. 
This categorisation corresponds roughly to the quintiles in the weighted data set. The first group is smaller than the other categories (14\%) to allow us to differentiate between negative and positive net worth. ${ }^{1}$

\section{Financial Resources: Income}

We use the average of the net household monthly income over the first three waves and equivalise it to the household size using the OECD-modified scale. The reported equivalised household incomes range from 506 EUR to 10,902 EUR per month. Like for parental wealth, we categorise equivalised household income into five categories:

(1) Income-poor / 1. Quintile [506 EUR; 980 EUR),

(2) 2. Quintile [980 EUR; 1,389 EUR),

(3) 3. Quintile [1,389 EUR; 1,694 EUR),

(4) 4. Quintile [1,694 EUR; 2,111 EUR),

(5) 5. Quintile [2,111 EUR; 10,902 EUR].

The first threshold corresponds to $60 \%$ of the median equivalised household income in Germany in 2013 (Statistisches Bundesamt 2019). Households below this threshold count as income-poor. As for the categorisation of wealth, this first group (16\%) is slightly smaller than the other groups.

\footnotetext{
${ }^{1}$ We use this parsimonious way to model non-linearities to keep the mediation analysis with multiple mediators comprehendible. With non-linear total effects, there are different indirect effects for each potential wealth (or income) contrast. Additionally, using the five net worth and income categories results in better model fit (AIC) and captures more variance in children's academic abilities than when using linear, quadratic, or cubic specifications for income and net worth.
} 


\section{Mediator: Neighbourhood}

We chose mediators and the time-point of measurement (when multiple measures were available) based on our theoretical model presented in Figure 1. Whenever possible, we measured the proposed mediators with multiple items and applied factor analysis to items that are supposed to measure latent constructs. The measurements of all mediators are summarised in Table 1, including all items used, the wave of their measurement, and the type of factor analysis applied.

We operationalise the quality of a neighbourhood with five variables about the composition of the neighbourhood, like the share of academics, an index of its purchasing power and the unemployment rate. This data was provided by a private marketing firm (Schönberger and Koberg 2017) for the time when the first wave took place. Except for the unemployment rate, all variables were measured on the street-level. Unlike the items assessed in the survey, the neighbourhood variables were not constructed to measure one latent construct. Therefore, we applied (exploratory) principal factor analysis. We extract the first factor to measure the composition of the neighbourhood, which captures most of the common variance of the variables (Eigenvalue $=3.21 ; \mathrm{KMO}=0.81$ ).

\section{Mediator: Educational Norms and Aspirations}

On the one hand, we use measures of parents' general attitude towards education by applying confirmatory factor analysis (CFA) on items like 'To go to school is a waste of time' (Cronbach's $\alpha=0.56$ ). On the other hand, we consider parents' idealistic aspirations for the school leaving certificate of the child. Here we only distinguish between aspirations for the 
highest school leaving certificate and all other certificates. Both, parents' attitudes and their aspirations were only measured in the fourth wave. ${ }^{2}$

\section{Mediator: Parental Stress}

We use the mothers' self-reported feelings to measure parental stress. In the second wave, mothers were surveyed about depressive feelings, whether they feel like they are running out of energy, whether they feel restricted by their role as a mother, and whether they feel lonely (Cronbach's $\alpha=0.67)$. We apply CFA to these items.

\section{Mediator: Mother-Child Interaction Quality}

To measure the interaction quality, mothers were given age-adequate toys and were asked to 'play with the child as you would normally do, if you were alone with the child and have some time to play'. This semi-standardised play situation was recorded on video and the video material was later rated with respect to different interaction behaviours of mother and child (for more details see A. Linberg et al. 2019). Here, we use the ratings of interaction in the third wave, the last wave that these measures took place. At this point, children were on average 27 months old. We apply CFA on the rating of mother's sensitivity to non-distress, positive attention, emotionality, and sensitivity (Cronbach's $\alpha=0.70$; Weinert et al. 2016).

${ }^{2}$ An earlier measurement of parents' attitudes and aspirations would have been preferable with respect to our theoretical model. With the available measurement of parents' attitudes and aspirations, we have to assume that these attitudes are reasonably time-constant and not affected by parental stress and parenting style. The weak association between parents' attitudes and aspirations with parental stress and parenting style seem to support this. 


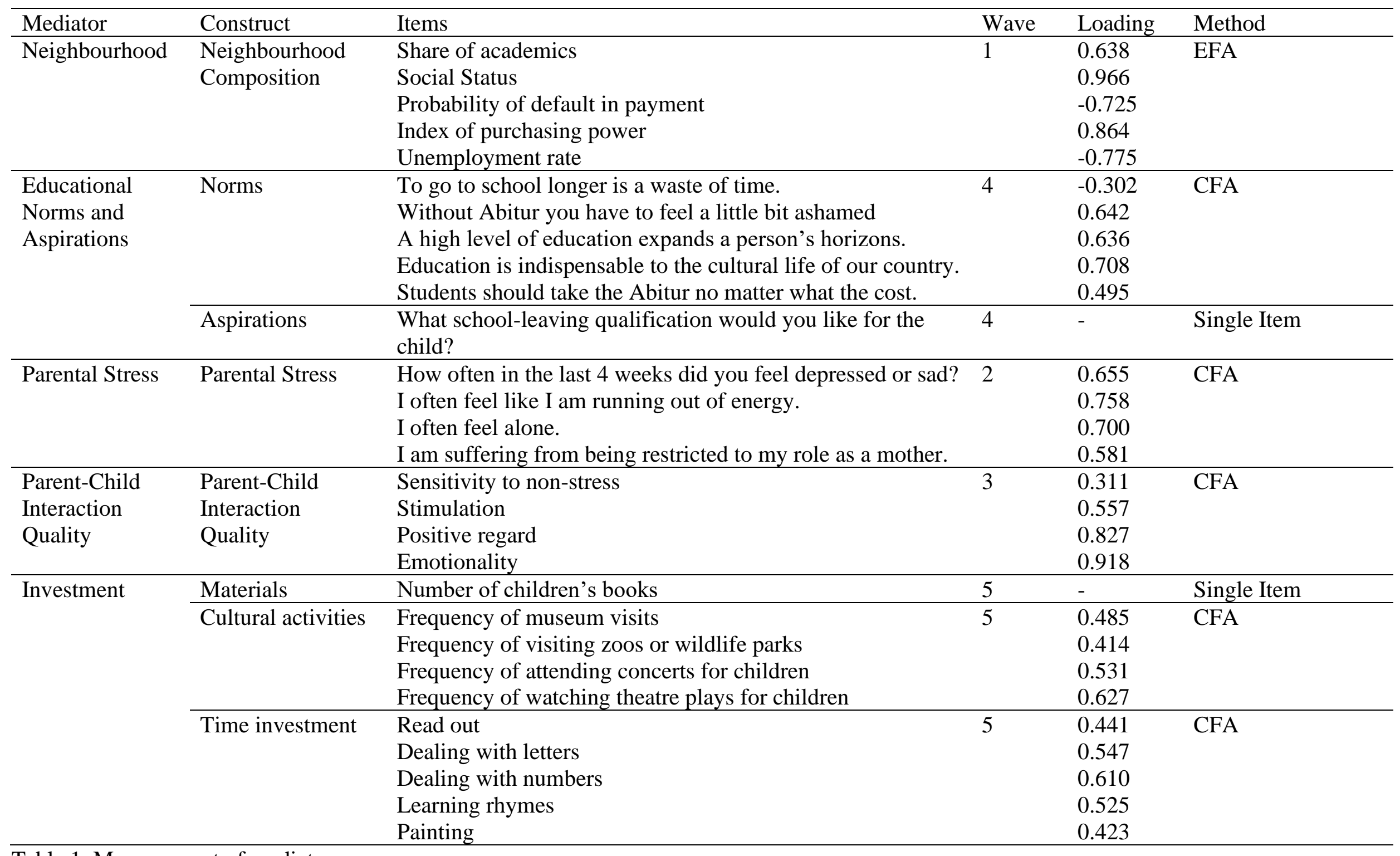

Table 1. Measurement of mediators 
NEPS, starting cohort Newborns. N=2,377. Weighted and averaged over 50 imputed datasets. EFA = Exploratory factor analysis; CFA = Confirmatory factor analysis. 


\section{Mediator: Investment}

We measure different aspects of parental investment using three constructs: materials, investment in cultural activities and time investment in joint activities. All items were measured in wave five. For investment in material, NEPS only offers the number of children's books. Time investment is measured by the frequency of different learning-related activities like reading to the child or showing them letters (Cronbach's $\alpha=0.57$ ). Investment in cultural activities is measured using four items that assess the frequency of different activities, like visiting concerts or theatres for children (Cronbach's $\alpha=0.53$ ). Unlike the time investment, these activities are usually not free of costs for parents. For parental investment in learningrelated activities and investment and cultural activities, we apply CFA.

\section{Control Variables}

To get unbiased estimates for the mediation analysis we have to control for all potential confounders between parents' financial resources, mediators, and children's academic abilities. Therefore, we control for parents' highest education (ISCED) and occupational class (EGP), migration status, age, marital status, family structure, number of siblings, child's gender, child's age, and whether the family lives in east or west Germany. Controlling for parental education and occupational class is necessary because we are only interested in the effect of financial resources and not in other advantages that may be associated with high socioeconomic status.

All these variables were measured in the first wave. Descriptive statistics of parents' income and wealth and all control variables are provided in Table A1.

\section{Analysis Plan}

In a first step, we estimate the differences in children's test scores (Math, PPVT, and Science; $Y$ ) by parents' financial resources (income and net worth; $A$ ) using ordinary least squares 
(OLS) regressions. In these models, we include both income and net worth ${ }^{3}$ and all the control variables $(C)$.

In a second step, we apply causal mediation analysis. In causal mediation analysis, the focus of interest is usually on the natural indirect effects (NIE) and the remaining natural direct effects. NIEs are defined as the difference in an outcome that would have occurred if the individuals had the observed values of exposure $(\alpha)$, but the values of a mediator $(M)$ that would have arisen under a counterfactual level of exposure $\left(M_{\alpha^{*}}\right)$, instead of the observed values for exposure and mediator $\left(M_{\alpha}\right): E\left[Y_{\alpha M_{\alpha}}-Y_{\alpha M_{\alpha^{*}}}\right]$

Four no confounding assumptions must hold to get unbiased estimates (VanderWeele 2015):

(1) There are no unmeasured confounders of the relation between exposure and outcomes;

(2) There are no unmeasured confounders of the relation between exposure and mediators;

(3) There are no unmeasured confounders of the relation between mediators and outcomes;

(4) There is no mediator-outcome confounder that is affected by the exposure.

If these assumptions hold, estimates can be interpreted as causal effects. ${ }^{4}$ Due to the rich set of control variables, we assume that assumptions 1-3 hold. Therefore, we will talk

${ }^{3}$ A high income may allow households to accumulate more wealth, and, at the same time, returns to investment may generate income. We decided to include both income and net worth in the same model to get conservative estimates for their unique contributions (see Pfeffer 2018 and Moulton et al. 2021 for a similar approach). Total differences are only slightly larger when excluding net worth for the estimation of income effects and vice versa (see appendix E).

${ }^{4}$ Additionally, we must make consistency and positivity assumptions (Hernán and Robins 2020). For mediation analysis, these assumptions also apply to all mediators (Zhou 2021). We evaluate the common support for net worth, income, and all mediators in the appendix $\mathrm{C}$ by comparing the distribution of the propensity scores between exposed and non-exposed cases. If certain ranges of propensities are only observed for exposed or non-exposed cases this indicates a lack of common 
about indirect effects from here on. Potential violations of these assumptions are addressed in the discussion.

Unlike assumptions 1-3, assumption 4 also applies to observed mediator-outcome confounders. Therefore, only the joint indirect effect via all mediators together and the NIE via the first mediator in the causal chain, here the neighbourhood, are statistically identified (VanderWeele, Vansteelandt, and Robins 2014). The NIEs via educational norms and aspirations, stress, parent-child interaction quality, and parental investment are not statistically identified because there are mediators earlier in the causal chain. On the one hand, we have to control for these early mediators, like the neighbourhood, when estimating the effect of the other mediators on the outcome because the neighbourhood is a confounder of the association between the other mediators and the outcome (e.g., Investment $\leftarrow$ Neighbourhood $\rightarrow$ Academic Abilities). On the other hand, we must not control for the neighbourhood because this would capture a part of the indirect effect of these other mediators (e.g., Financial Resources $\rightarrow$ Neighbourhood $\rightarrow$ Investment $\rightarrow$ Academic Abilities). Either way, the results will be biased.

Therefore, we follow the sequential joint mediation approach by VanderWeele, Vansteelandt, and Robins (2014) and estimate partial indirect effects (PIE) for these mediators. PIEs give us the indirect effects through a specific mediator that bypasses all prior mediators (Steen et al. 2017). It shows us how much of the total effect of parents' financial resources we could erase by a hypothetical intervention that sets the effect of financial resources on this mediator to zero.

support. The propensities of exposed and non-exposed cases largely overlap for net worth and most mediators. Only for income-poverty and low values in learning materials, there are few non-exposed cases with high propensities. Estimates for these cases are based on extrapolations. 
This decomposition is achieved by comparing joint indirect effects in a nested subset of mediators:

(1) Neighbourhood,

(2) Neighbourhood + Educational Norms \& Aspirations,

(3) Neighbourhood + Educational Norms \& Aspirations + Parental Stress,

(4) Neighbourhood + Educational Norms \& Aspirations + Parental Stress + Parent-child Interaction Quality,

(5) Neighbourhood + Educational Norms \& Aspirations + Parental Stress + Parent-child Interaction Quality + Investment.

The indirect effect in model 5 gives us the joint indirect effect via all mediators together and the indirect effect in model 1 gives us the NIE of neighbourhood. PIEs can be estimated as the difference in indirect effects between consecutive models: The PIE of educational norms and aspirations can be estimated as the difference in the indirect effects between model 1 and 2, PIE of parental stress as the differences between model 2 and 3, PIE of parent-child interaction quality as the differences between model 3 and 4, and the PIE of investment as the difference between model 4 and 5. Note that NIE and PIE also capture indirect effects via mediators later in the causal chain. For instance, the NIE of neighbourhood also captures indirect effects like Financial Resources $\rightarrow$ Neighbourhood $\rightarrow$ Investment $\rightarrow$ Academic Abilities (see also appendix B for a graphical presentation of all indirect effects).

We use 'Natural Effect Models' to estimate direct and indirect effects (Steen et al. 2017). The underlying idea of this approach is to impute nested counterfactual values for the outcomes $\left(Y_{\alpha M_{\alpha^{*}}}\right)$ and then estimating direct and indirect effects by regressing $Y_{\alpha M_{\alpha^{*}}}$ on the actual exposure $(a)$ and the counterfactual exposure $(a *)$ (for more details see Vansteelandt, Bekaert, and Lange 2012, and Steen et al. 2017). We use lasso regressions to select the 
covariates (Tibshirani 1996) for the imputation of $Y_{\alpha M_{\alpha^{*}}}$ from the set of financial resources, control variables, mediators, interaction-terms between financial resources and mediators (i.e., exposure-mediator interactions), and interaction-terms among the mediators. We choose the penalisation parameter that yields the lowest AIC for the lasso regressions.

Standard errors are estimated using bootstraps on the imputed data (Schomaker and Heumann 2018). Individuals are sampled into the bootstrap by the inverse of their probability to be included in the analysis sample.

\section{Results}

\section{Differences in Academic Abilities by Financial Resources}

Results for all four measures of academic abilities are presented in Figures 2.1 to 2.4. We see substantial differences for all measures of children's academic abilities by both parental income and net worth (see 'Total Differences' in Figures 2.1 to 2.4). Already at an age of four years, children in income-poor households score 0.22 standard deviations (SD) lower in the standardised math test scores than children living in households with the highest incomes. Similarly, children in income-poor households score up to 0.30 SD lower in the math test at an age of six, up to 0.23 SD lower in science, and up to 0.34 SD lower in PPVT.

A similar pattern emerges for parental net worth, but with smaller effect sizes.

Children with a negative net worth score up to 0.22 SD lower in the math test at an age of four, up to $0.23 \mathrm{SD}$ lower in math at an age of six, and up to $0.24 \mathrm{SD}$ lower in the science test. Differences in PPVT scores are much smaller and none of them is statistically significant. ${ }^{5}$

\footnotetext{
${ }^{5}$ Raw differences (without adjusting for control variables) by income are up to three times larger and raw differences by wealth are up to two times larger than the adjusted differences (see appendix D).
} 
The differences in academic abilities by parents' financial resources are non-linear. The largest contrast appears between children growing up in households below the incomepoverty threshold and children growing up in households above this threshold. The differences in academic abilities among children in the second to fifth income quintile are much smaller. For instance, for math test scores at age four, children in households in the second income-quintile score 0.211 SD higher (95\%-CI: $0.012-0.408)$, while children in the fifth income-quintile score 0.224 SD higher (95\%-CI: 0.002 - 0.440) compared to incomepoor children.

Likewise, for parental net worth, we see the largest contrasts between children in households with negative net worth and children in households with zero or positive net worth. Moreover, we see for all outcomes that children in the highest net worth quintile score lower than children in the fourth net worth quintile. This pattern is most pronounced for math test scores at an age of six. Children in the second net worth quintile score 0.110 SD higher (95\%-CI: $-0.058-0.284$ ), and children in the fourth net worth quintile even 0.230 SD higher (95\%-CI: $0.041-0.436)$ than children in households with negative net worth. However, children in the highest net worth quintile score only 0.131 SD higher (95\%-CI: -0.073 - 0.338) than children in households with negative net worth, and, thus, almost 0.10 SD lower than children in the fourth net worth quintile. Importantly, all these differences emerge after controlling for the comprehensive set of other parental characteristics. 

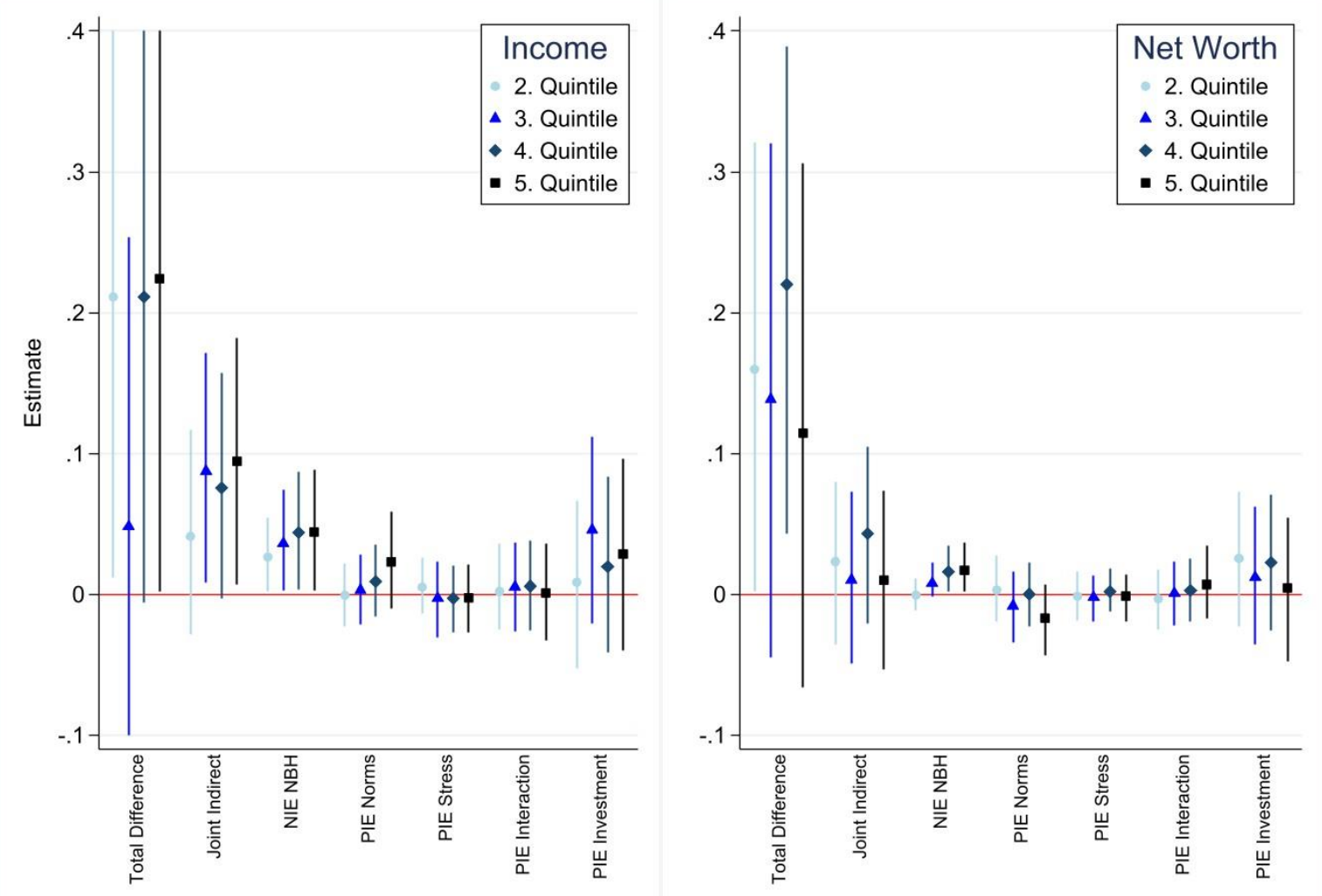

Figure 2.1. Mediation analysis of math test scores differences by parental income and wealth at age four

NEPS, starting cohort Newborns. N=2,377. Weighted and averaged over 50 imputed datasets.

Reference categories: Income $=$ Income-poor. Net Worth $=$ Negative. 

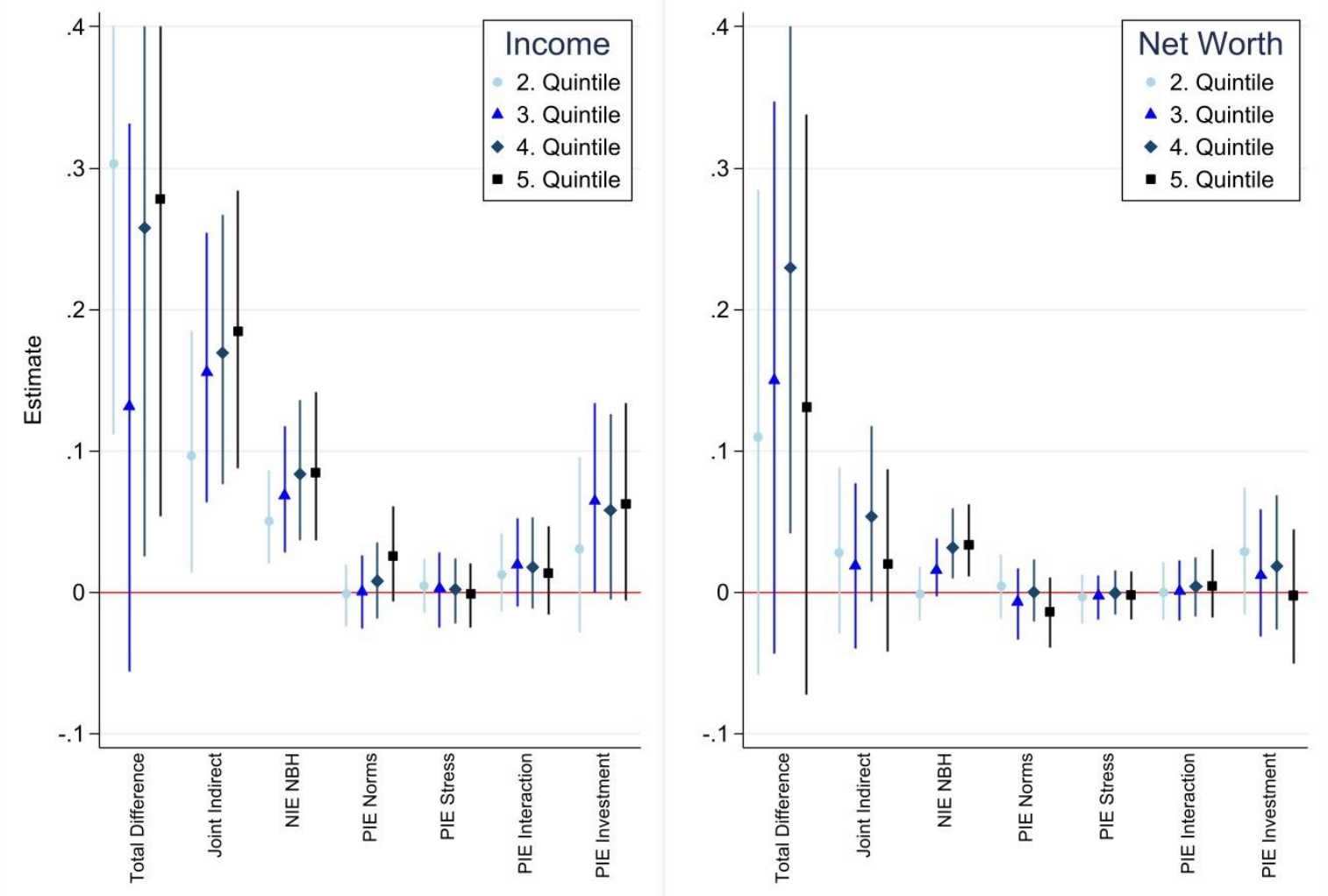

Figure 2.2. Mediation analysis of math test scores differences by parental income and wealth at age six

NEPS, starting cohort Newborns. $\mathrm{N}=2,377$. Weighted and averaged over 50 imputed datasets.

Reference categories: Income $=$ Income-poor. Net Worth $=$ Negative. 

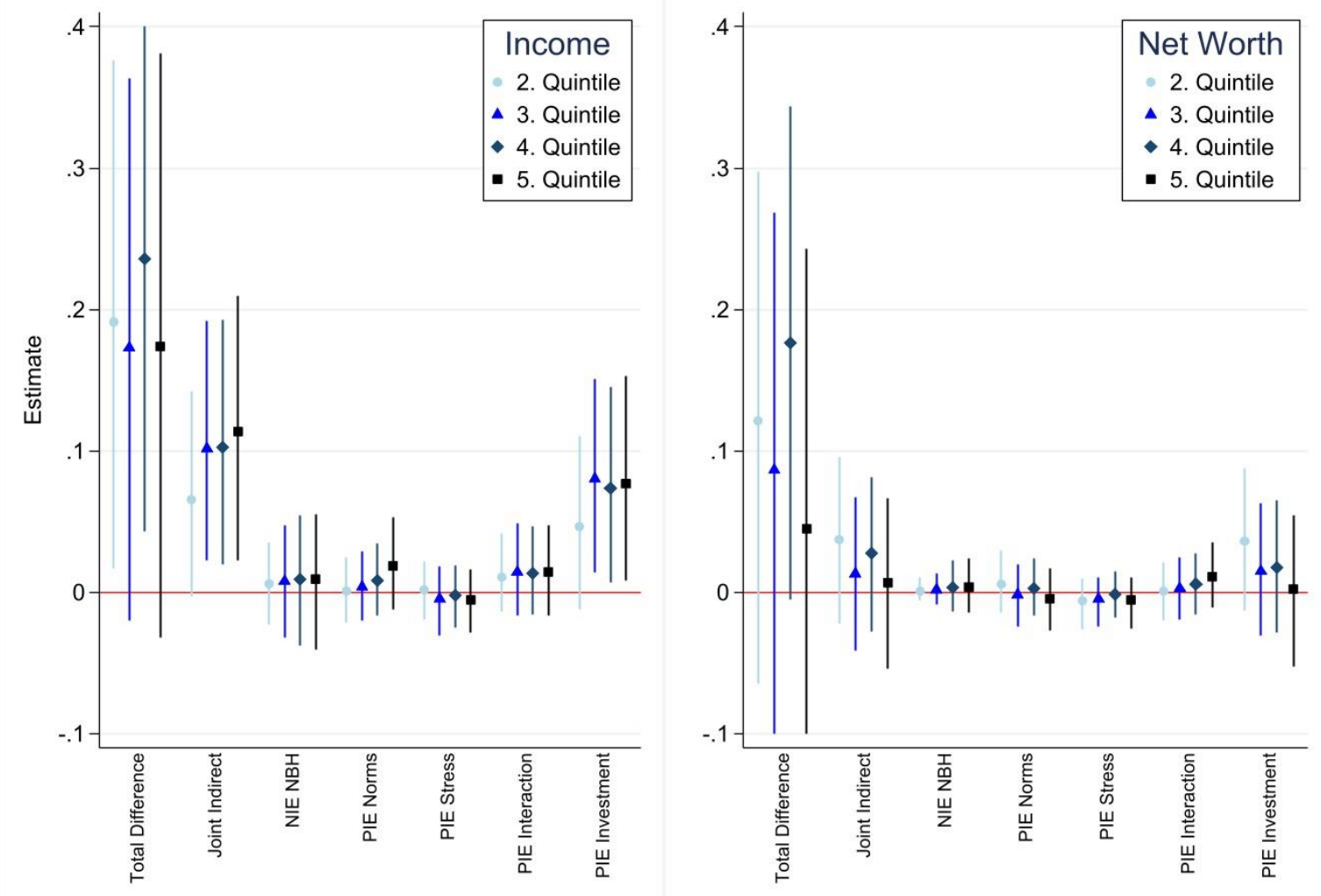

Figure 2.3. Mediation analysis of science test scores differences by parental income and wealth

NEPS, starting cohort Newborns. N=2,377. Weighted and averaged over 50 imputed datasets.

Reference categories: Income $=$ Income-poor. Net Worth $=$ Negative. 

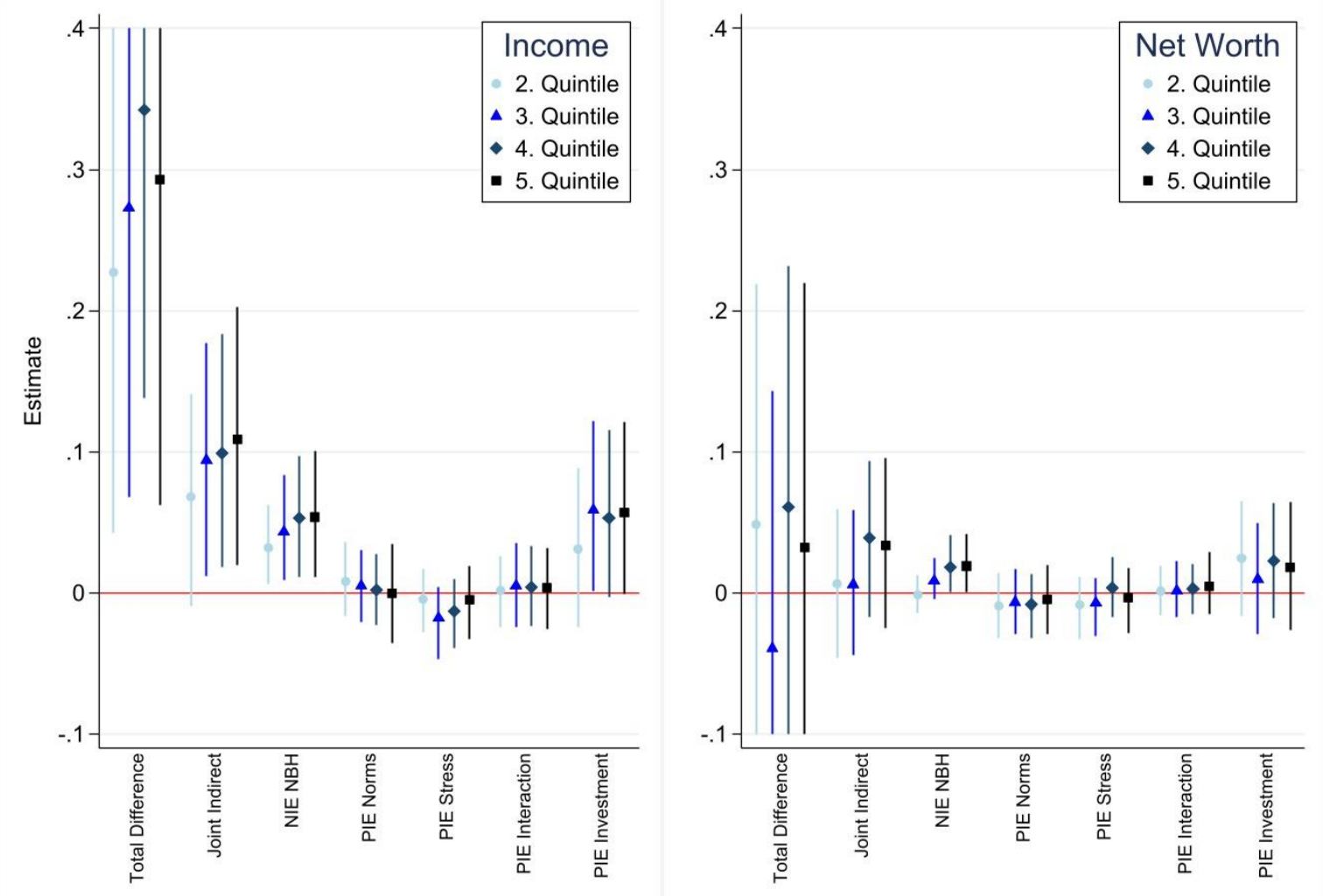

Figure 2.4. Mediation analysis of PPVT scores differences by parental income and wealth NEPS, starting cohort Newborns. N=2,377. Weighted and averaged over 50 imputed datasets. Reference categories: Income $=$ Income-poor. Net Worth $=$ Negative. 


\section{Mediation Analysis}

In the next step, we analyse which factors mediate these differences in academic abilities by parents' financial resources. In general, we see that the indirect effects are much more consistent over the different measures of academic abilities than the total income differences. Moreover, in contrast to the total differences, all joint indirect effects are statistically significant. All mediators together mediate between 0.041 and $0.097 \mathrm{SD}$ of the difference between children in income-poor households and children in the second income quintile and even 0.094 to $0.185 \mathrm{SD}$ of the differences between children in income-poor households and children in the highest income quintiles (see 'Joint Indirect' in Figures 2.1 to 2.4). On average, all mediators together account for $47 \%$ of the disparities by parental income. ${ }^{6}$

Parental investment and the composition of the neighbourhood seem to be the most important mediators of income differences. Differences in parental investment account for 0.031 to $0.080 \mathrm{SD}$ of the income differences for math (age 6), science and PPVT scores. Indirect effects via investment are less relevant for math test scores at age 4 (see 'PIE Investment'). On average, $23 \%$ of the differences by parental income can be attributed to parental investment.

The neighbourhood composition mediates between 0.026 and $0.054 \mathrm{SD}$ of the income differences in math test and PPVT scores (see 'NIE NBH'). This corresponds, on average, to $23 \%$ of the total differences for these outcomes.

All other indirect effects are much smaller and occur only for some measures of academic abilities and some income contrasts. Parents' educational norms mediate a small share of the difference between children in the highest quartile in contrast to the lowest

\footnotetext{
${ }^{6}$ We only consider outcomes and income / wealth contrasts, for which the Total Difference is larger than 0.1 for the calculation of the average proportion mediated.
} 
quintile for math test scores at age four (PIE $=0.023$; 95\%-CI: $-0.010-0.058)$ and math test scores at age six (PIE=0.025; 95\%-CI: -0.006-0.060). Lastly, there are small indirect effects via parent-child interaction quality for math test scores at age six and science test scores. Yet, it is important to keep in mind that all indirect effects except for the PIE via parental investment also include indirect effects via the mediators later in the causal chain (see appendix B).

The indirect effects of wealth differences are much smaller than indirect effects of income differences and most are not statistically significant. The largest joint indirect effect emerges for the contrast between children in the fourth net worth quintile and children in households with negative net worth: 0.032 SD (95\%-CI: -0.021 - 0.105) for math test scores at age four, $0.053 \mathrm{SD}(95 \%-\mathrm{CI}$ : $-0.007-0.117)$ for math test scores at age six, and $0.039 \mathrm{SD}$ (95\%-CI: -0.017 - 0.094) for PPVT scores. On average, all mediators together account for $17 \%$ of the total difference in academic abilities by parental net worth.

Like for income, the most important mediators seem to be parental investment (on average $12 \%$ of total differences by wealth) and neighbourhood effects (on average $8 \%$ ). Surprisingly, differences in parental investment seem to contribute most to the differences in academic abilities between children in the second net worth quintile and children in households with a negative net worth (e.g., for science: 0.036 SD; 95\%-CI: -0.013 - 0.088) and less for the differences between children in the households with the highest net worth in contrast to those with negative net worth.

Indirect effects via the neighbourhood composition emerge only for math and PPVT scores. The largest indirect effect emerges for the differences in math test scores at age six for the contrast between children in the highest net worth quintile and children in households with negative net worth: 0.034 SD (95\%-CI: 0.011 - 0.062). Indirect effects of parental net worth 
via parental Stress, mother-child interaction quality, and educational norms and aspirations seem to be negligible.

We would have gotten different results if we had used the difference method instead of the sequential mediation approach (see Table 2). Recall that the results of these two methods may differ for two reasons: 1) interdependencies between the mediators and 2) interactions between financial resources and mediators or interactions among the mediators.

We observe four main differences when comparing the results of the two methods. First, when using the sequential mediation approach, the joint indirect effect equals the sum of the indirect effects via the five mediators (by definition). This is not the case for the difference method. The sum of the indirect effects via neighbourhood, norms, parental stress, interaction quality and parental investment is $0.011 \mathrm{SD}$ larger than the joint indirect effect for income and 0.005 SD larger for wealth when using the difference methods. Second, on average over all outcomes, the difference method overestimates the indirect effect via parental investment by 0.01 SD (see row 'Investment', column 'Average of differences' in Table 2) i.e., by about 20\%. Third, the joint indirect effects of income differ between the methods on average by 0.009 SD (row 'Joint indirect', column 'Average of absolute difference'). However, the average difference between the methods is almost zero because of overestimations for some outcomes but underestimations for other outcomes. Lastly, the standard errors of the indirect effect estimates are larger when applying the sequential mediation analysis. For example, the standard errors of the joint indirect effects are 1.4 times larger when using the sequential mediation approach than when using the difference method. This reflects the bias-variance trade-off that we face when allowing for exposure-mediator and mediator-mediator interactions in the sequential mediation approach, which are assumed to be zero when using the difference method. 


\begin{tabular}{lccc}
\hline & $\begin{array}{c}\text { Average of } \\
\text { differences }\end{array}$ & $\begin{array}{c}\text { Average of absolute } \\
\text { differences }\end{array}$ & Ratio of SEs \\
\hline Income & -0.001 & 0.009 & 1.425 \\
Joint Indirect & 0.000 & 0.003 & 1.028 \\
NBH & 0.001 & 0.003 & 1.709 \\
Norms & -0.003 & 0.005 & 3.285 \\
Stress & -0.001 & 0.003 & 1.756 \\
Interaction Quality & -0.010 & 0.010 & 1.548 \\
Investment & & & \\
Net Worth & -0.002 & 0.006 & 1.480 \\
Joint Indirect & 0.001 & 0.001 & 1.164 \\
NBH & -0.004 & 0.004 & 1.379 \\
Norms & -0.002 & 0.003 & 1.703 \\
Stress & 0.000 & 0.002 & 1.504 \\
Interaction Quality & -0.002 & 0.005 & \\
Investment & & & \\
\hline
\end{tabular}

Table 2. Difference between indirect effects with the sequential mediation approach and the difference method.

Differences averaged over all four outcomes and four income / net worth contrasts. Average of differences $=$ Indirect effects obtained with sequential mediation approach - Indirect effect obtained with difference method. Ratio of SEs $=$ Standard errors of the indirect effects obtained with the sequential mediation approach / standard errors of the indirect effects obtained with the difference method. 


\section{Discussion}

In this paper, we evaluate the association between parents' financial resources and the academic abilities of pre-school children in Germany and test potential mediators of these associations. Even when controlling extensively for other socio-demographic parental characteristics, we find that children growing up in income-poor households score up to 0.33 SD lower in math, science and PPVT. Yet, differences by income do not give the complete picture of the stratification by parents' economic resources: On top of the differences by parental income, we also find a substantial difference in math and science test scores by parental wealth. Consistently with the literature (Elliott, Destin, and Friedline 2011), we do not find wealth differences in PPVT scores.

Both, differences by parental income and wealth emerge particularly at the lower end of the distribution. Children in income-poor households or households with negative net worth score substantially worse than their peers above these thresholds. This threshold effect is in line with other research on income effects in Germany (e.g., Schneider 2004). Thus, a lack of financial resources hinders children's academic abilities, while more financial resources do not result in higher academic abilities once families have surpassed a relatively low threshold.

Based on the existing literature, we test five potential mediators of the association between parents' financial resources and children's academic abilities: family investment, parental stress and parenting, neighbourhood effects, and educational norms and aspirations. Importantly, these different mediators are interdependent, which has to be considered for their analysis. Traditional approaches to mediation analysis give biased results if mediators are causally related.

Applying a sequential joint mediation approach, we find that all mediators together explain on average $47 \%$ of the differences in academic abilities by parental income, but only 
$17 \%$ of the differences by parental wealth. The most important mediator of the differences by parents' financial resources is parental investment. This finding is in line with existing results which demonstrate that investment is more important in driving income effects on academic abilities than family stress and parenting behaviour (Guo and Harris 2000; Yeung, Linver, and BrooksGunn 2002). Besides family investment, the most important mediator seems to be the neighbourhood composition. One explanation for this could be that the neighbourhood composition will be reflected in the composition of day-care groups, which have been shown to affect children's cognitive development (Becker and Schober 2017). Parents' educational norms and aspirations, their stress levels and the parent-child interaction quality do not seem to contribute substantially to differences in academic abilities by parents' economic resources, even when considering their indirect effects on parental investment behaviour. Particularly the negligible contribution of educational aspirations stands in strong contrast to the finding of Diemer, Marchand, and Mistry (2020) for the US. One explanation for this could be that Diemer, Marchand, and Mistry (2020) did not consider other mediators. Moreover, educational aspirations may become more important for educational decisions when children are older.

Overall, our results raise the question as to why the proposed mediators explain a much smaller proportion of the wealth differences than they do for income differences. This finding highlights again that wealth differences in academic abilities are caused by other underlying mechanisms than income differences. Further mechanisms that may drive wealth effects may be housing conditions and housing stability. Housing is by far the largest component of the wealth portfolio of most households (Grabka and Westermeier 2014). At the same time, it has been shown that child development is harmed by bad housing conditions and instability (Evans 2006; Ziol-Guest and McKenna 2014). Housing quality was, however, not evaluated in NEPS. 
Importantly, our results have to be interpreted in the context of Germany, where children's differences in academic ability resulting from other socioeconomic characteristics of their parents - like their parents' educational levels - are larger than differences caused by financial resources. The extent to which these results can be generalised to other countries remains an open question. The magnitude of disparities in academic abilities will vary according to how stratified the mediators are by financial resources.

Some limitations should be considered for the interpretation of our results. First, even though a comprehensive set of variables was measured in NEPS, the timing of measurement was not optimal for our research questions. Parental wealth was only measured in the third wave. Although wealth could have potentially changed during this time and may have been affected by the neighbourhood in which parents live, we assume that no large bias arises from this because of our categorical operationalisation of net worth and because there were no substantial changes to the distribution of wealth during this period (Grabka and Westermeier 2014). A similar argument applies to parents' educational norms, which were measured only in the fourth wave. Nevertheless, the potential bias arising from this would not change the substantive results, because the association of norms with all outcomes and mediators is negligible small.

Second, both parents' financial resources, particularly wealth, and mediators are probably measured with error. Wealth was self-reported by parents, which is often inaccurate (Goodman and Ittner 1992). Measurement error in parents' financial resources will lead to an underestimation of the total differences in children's academic abilities (Mazumder 2005). Since wealth is likely measured with more error than income, underestimation will be larger for wealth. Among the mediators, particularly parents' investment in learning materials could have been measured in more detail. Measurement error in mediators will lead to an underestimation of the indirect effects (VanderWeele 2015). 
Third, the interpretation of the results of the mediation analysis depends crucially on whether its assumptions are met, particularly that there are no unmeasured confounders. One potential unmeasured confounder of parents' economic resources and children's academic abilities could be parents' cognitive and non-cognitive competencies, which were not assessed in NEPS. Although parents' competencies may be partly captured by parents' education and occupational class, this could have resulted in an overestimation of effects. However, if only parents' economic resources and children's academic abilities are confounded, only total differences and direct effects are biased, while the indirect effects remain unbiased. If this were the case, we could apply the front-door criterion (Pearl 2009) and interpret the joint indirect effect as an unbiased estimate of parents' economic resources' effect.

Fourth, as already mentioned in the background section, there may be additional causal paths between mediators that we did not consider, like educational norms affecting the choice of the residence. Testing these additional pathways would require longitudinal data on all mediators.

Despite these limitations, our research suggests once more that wealth is a unique dimension of social stratification and that ignoring it may lead to an underestimation of inequalities. Yet, even when using a rich set of the proposed mediators of wealth differences, surprisingly little of the differences can be explained. To reduce the stratifying consequences of wealth inequality, further research is needed to test the underlying mechanisms of wealth stratification in other contexts and to test further potential mediators like housing conditions.

Moreover, our results highlight that individual mediating factors of social stratification cannot be studied in isolation when mediators are causally related. Not including a mediator which occurs early in the causal pathway may cause confounding between later mediators and the outcome. The problem of causally related mediators does not only apply to our analysis 
but to most mediation processes in the social sciences. The bias from ignoring other mediators will be particularly severe in contexts where mediators are strongly related. 


\section{References}

Attig, Manja, and Sabine Weinert. 2018. "Soziale Disparitäten im Kontext von Mutter-KindInteraktionen und frühen Entwicklungsmaßen von Kindern [Social Disparities, Measures of Mother-Child Interaction and Early Learning Resources in the Second Year of Life Evidence from the Newborn Cohort Study of the NEPS].” Frühe Bildung 7 (1): 22-31. doi:10.1026/2191-9186/a000356.

Baron, Reuben M., and David A. Kenny. 1986. "The moderator-mediator variable distinction in social psychological research: conceptual, strategic, and statistical considerations". Journal of Personality and Social Psychology 51 (6): 1173-1182.

Becker, Birgit, and Pia Sophia Schober. 2017. "Not Just Any Child Care Center? Social and Ethnic Disparities in the Use of Early Education Institutions with a Beneficial Learning Environment.” Early Education and Development 28 (8): 1011-1034. doi:10.1080/10409289.2017.1320900.

Becker, Gary S., and Nigel Tomes. 1986. "Human Capital and the Rise and Fall of Families." Journal of Labor Economics 4 (3, Part 2): S1-S39. doi:10.1086/298118.

Biedinger, Nicole. 2011. "The Influence of Education and Home Environment on the Cognitive Outcomes of Preschool Children in Germany." Child Development Research 2011: 1-10. doi:10.1155/2011/916303.

Blossfeld, Hans-Peter, Hans-Günther Roßbach, and Jutta von Maurice. 2011. "Education as a Lifelong Process the German National Educational Panel Study (NEPS).” Zeitschrift für Erziehungswissenschaft 14. doi:10.1007/s11618-011-0179-2.

Brown, Sarah, Karl Taylor, and Stephen Wheatley Price. 2005. "Debt and Distress: Evaluating the Psychological Cost of Credit." Journal of Economic Psychology 26 (5): 642-663. doi:10.1016/j.joep.2005.01.002.

Statistisches Bundesamt. 2019. Private Schulen - Fachserie 11 Reihe 1.1 - Schuljahr $2018 / 2019$.

Burgette, Lane F., and Jerome P. Reiter. 2010. "Multiple Imputation for Missing Data via Sequential Regression Trees.” American Journal of Epidemiology 172 (9): 10701076. doi:10.1093/aje/kwq260.

Coley, Rebekah Levine, Bryn Spielvogel, Claudia Kruzik, Portia Miller, Laura Betancur, and Elizabeth Votruba-Drzal. 2021. "Explaining Income Disparities in Young Children's Development: The Role of Community Contexts and Family Processes." Early Childhood Research Quarterly 55: 295-311. doi:10.1016/j.ecresq.2020.12.006. 
Conger, Rand D., and Katherine J. Conger. 2002. "Resilience in Midwestern Families: Selected Findings from the First Decade of a Prospective, Longitudinal Study." Journal of Marriage and Family 64 (2): 361-373. doi:10.1111/j.17413737.2002.00361.x.

Conley, Dalton. 2001. "Capital for College: Parental Assets and Postsecondary Schooling." Sociology of Education 74 (1): 59-72. doi:10.2307/2673145.

Dahl, Gordon B, and Lance Lochner. 2012. "The Impact of Family Income on Child Achievement: Evidence from the Earned Income Tax Credit." American Economic Review 102 (5): 1927-1956. doi:10.1257/aer.102.5.1927.

Davis-Kean, Pamela E. 2005. "The Influence of Parent Education and Family Income on Child Achievement: The Indirect Role of Parental Expectations and the Home Environment." Journal of Family Psychology 19 (2): 294-304. doi:10.1037/08933200.19.2.294.

Diemer, Matthew A., Aixa D. Marchand, and Rashmita S. Mistry. 2020. "Charting How Wealth Shapes Educational Pathways from Childhood to Early Adulthood: A Developmental Process Model.” Journal of Youth and Adolescence 49: 1073-1091. doi:10.1007/s10964-019-01162-4.

Dräger, Jascha. 2021. “The Role of Parental Wealth in Children's Educational Pathways in Germany.” European Sociological Review. doi: 10.1093/esr/jcab027.

Dräger, Jascha, and Nora Müller. 2020. "Wealth Stratification in the Early School Career in Germany." Research in Social Stratification and Mobility 67 (100483). doi:10.1016/j.rssm.2020.100483.

Duncan, Greg J., and Richard J. Murnane, eds. 2011. Whither Opportunity? Rising Inequality, Schools, and Children's Life Chances. New York : Chicago: Russell Sage Foundation; Spencer Foundation.

Dunn, Lucia F., and Ida A. Mirzaie. 2016. "Consumer Debt Stress, Changes in Household Debt, and the Great Recession.” Economic Inquiry 54 (1): 201-214. doi:10.1111/ecin.12218.

Elliott, William, Mesmin Destin, and Terri Friedline. 2011. "Taking Stock of Ten Years of Research on the Relationship Between Assets and Children's Educational Outcomes: Implications for Theory, Policy and Intervention." Children and Youth Services Review 33 (2011): 2312-2328. doi:10.1016/j.childyouth.2011.08.001. 
Evans, Gary W. 2006. "Child Development and the Physical Environment." Annual Review of Psychology 57 (1): 423-451. doi:10.1146/annurev.psych.57.102904.190057.

Feinstein, Leon. 2003. "Inequality in the Early Cognitive Development of British Children in the 1970 Cohort." Economica 70 (277): 73-97. doi:10.1111/1468-0335.t01-1-00272.

Friedline, Terri, Rainier D. Masa, and Gina A. N. Chowa. 2015. “Transforming Wealth: Using the Inverse Hyperbolic Sine (IHS) and Splines to Predict Youth's Math Achievement." Social Science Research 49: 264-287. doi:10.1016/j.ssresearch.2014.08.018.

Gershoff, Elizabeth T., J. Lawrence Aber, C. Cybele Raver, and Mary Clare Lennon. 2007. "Income Is Not Enough: Incorporating Material Hardship into Models of Income Associations with Parenting and Child Development." Child Development 78 (1): 7095. doi:10.1111/j.1467-8624.2007.00986.x.

Goodman, John L., and John B. Ittner. 1992. "The accuracy of home owners' estimates of house value." Journal of Housing Economics 2 (4): 339-357. doi:10.1016/10511377(92)90008-E.

Grabka, Markus M., and Christian Westermeier. 2014. "Persistently High Wealth Inequality in Germany.” DIW Economic Bulletin 4 (6): 3-15. doi:10.1007/s11150-013-9229-2.

Guo, Guang, and Kathleen Mullan Harris. 2000. “The Mechanisms Mediating the Effects of Poverty on Children's Intellectual Development.” Demography 37 (4): 17.

Hahn, Inga, Katrin Schöps, Silke Rönnebeck, Maike Martensen, Sabine Hansen, Steffani Saß, Inger Marie Dalehefte, and Manfred Prenzel. 2013. “Assessing Scientific Literacy over the Lifespan A Description of the NEPS Science Framework and the Test Development." Journal for Educational Research Online 5 (2): 110-138.

Hällsten, Martin, and Fabian T. Pfeffer. 2017. "Grand Advantage: Family Wealth and Grandchildren's Educational Achievement in Sweden." American Sociological Review 82 (2): 328-360. doi:10.1177/0003122417695791.

Hastie, Trevor, Robert Tibshirani, and Jerome Friedman. 2009. The Elements of Statistical Learning. Data Mining, Inference, and Prediction. New York: Springer.

Hayes, Timothy, Satoshi Usami, Ross Jacobucci, and John J. McArdle. 2015. "Using Classification and Regression Trees (CART) and Random Forests to Analyze Attrition: Results From two Simulations.” Psychology and Aging 30 (4): 911-929. doi: 10.1037/pag0000046. 
Hernán, Miguel A., and James M. Robins. 2020. Causal Inference: What If. Boca Raton: Chapman \& Hall/CRC.

Iruka, Iheoma U., Doré R. LaForett, and Erika C. Odom. 2012. "Examining the Validity of the Family Investment and Stress Models and Relationship to Children's School Readiness Across Five Cultural Groups.” Journal of Family Psychology 26 (3): 359370. doi:10.1037/a0028290.

Justice, Laura M., Yaacov Petscher, Christopher Schatschneider, and Andrew Mashburn. 2011. 'Peer Effects in Preschool Classrooms: Is Children's Language Growth Associated with Their Classmates' Skills?: Peer Effects." Child Development 82 (6): 1768-1777. doi:10.1111/j.1467-8624.2011.01665.x.

Karagiannaki, Eleni. 2017. “The Effect of Parental Wealth on Children's Outcomes in Early Adulthood." The Journal of Economic Inequality 15 (3): 217-243. doi:10.1007/s 10888-017-9350-1.

Kiernan, Kathleen E., and Fiona K. Mensah. 2011. "Poverty, Family Resources and Children's Early Educational Attainment: The Mediating Role of Parenting." British Educational Research Journal 37 (2): 317-336. doi:10.1080/01411921003596911.

Kim, Jae Hong, Francesca Paglaria, and John Preston. 2005. "The intention to move and residential location choice behavior". Urban Studies 42 (9): 1621-1636. https://doi.org/10.1080/00420980500185611.

Kim, Youngmi, Michael Sherraden, Jin Huang, and Margaret Clancy. 2015. "Child Development Accounts and Parental Educational Expectations for Young Children: Early Evidence from a Statewide Social Experiment." Social Service Review 89 (1): 99-137. doi:10.1086/680014.

Kluczniok, Katharina, Simone Lehrl, Susanne Kuger, and Hans-Guenther Rossbach. 2013. "Quality of the Home Learning Environment During Preschool Age Domains and Contextual Conditions." European Early Childhood Education Research Journal 21 (3): 420-438. doi:10.1080/1350293X.2013.814356.

Layte, Richard. 2017. "Why Do Working-Class Kids Do Worse in School? An Empirical Test of Two Theories of Educational Disadvantage.” European Sociological Review 33 (4): 489-503. doi:10.1093/esr/jcx054.

Leventhal, Tama, and Jeanne Brooks-Gunn. 2000. "The Neighborhoods They Live in: The Effects of Neighborhood Residence on Child and Adolescent Outcomes." Psychological Bulletin 126 (2): 309-337. doi:10.1037/0033-2909.126.2.309. 
Linberg, Anja, Daniel Mann, Manja Attig, Franziska Vogel, Sabine Weinert, and HansGünther Roßbach. 2019. Quality of Parent-Child Interactions - Assessment of Interaction with the Parent-Child-Interaction Rating System in the National Educational Panel Study at the Child's Age of 7, 17 and 26 Month. 51. Bamberg: Leibniz Institute for Educational Trajectories.

Linberg, Tobias, Thorsten Schneider, Jane Waldfogel, and Yi Wang. 2019. "Socioeconomic Status Gaps in Child Cognitive Development in Germany and the United States." Social Science Research 79 (March): 1-31. doi:10.1016/j.ssresearch.2018.11.002.

Mazumder, Bhashkar. 2005. "Fortunate Sons: New Estimates of Intergenerational Mobility in the United States Using Social Security Earnings Data." Review of Economics and Statistics 87 (2): 235-255. doi:10.1162/0034653053970249.

Moulton, Vanessa, Alissa Goodman, Bilal Nasim, George B. Ploubidis, and Ludovica Gambaro. 2021. "Parental Wealth and Children's Cognitive Ability, Mental, and Physical Health: Evidence from the UK Millennium Cohort Study." Child Development 92(1), 115-123. doi:10.1111/cdev.13413.

Mudiappa, Michael, and Katharina Kluczniok. 2015. "Visits to Cultural Learning Places in the Early Childhood.” European Early Childhood Education Research Journal 23 (2): 200-212. doi:10.1080/1350293X.2015.1016805.

Nievar, M. Angela, Amanda Kay Moske, Deborah Jean Johnson, and Qi Chen. 2014. "Parenting Practices in Preschool Leading to Later Cognitive Competence: A Family Stress Model." Early Education and Development 25 (3): 318-337. doi:10.1080/10409289.2013.788426.

Oeltjen, Mareike, and Michael Windzio. 2019. "Räumliche Segregation durch ungleiche Bildungskontexte?: Wahrgenommene Nachbarschaftsmerkmale und Umzüge von Familien [Spatial Segregation due to Unequal Educational Contexts? Perceived Neighborhood Characteristics and Moving of Families]." Kölner Zeitschrift für Soziologie und Sozialpsychologie 71 (4): 651-675. doi:10.1007/s11577-019-00641-7. Orr, Amy J. 2003. "Black-White Differences in Achievement: The Importance of Wealth." Sociology of Education 76 (4): 281-304. doi:10.2307/1519867.

Owens, Ann. 2018. "Income Segregation Between School Districts and Inequality in Students' Achievement." Sociology of Education 91 (1): 1-27. doi:10.1177/0038040717741180. 
Pearl, Judea. 2009. Causality: Models, Reasoning, and Inference. Cambridge: Cambridge University Press.

Peterson, Lara Aylin, and Anna-Lena Gerken. 2018. NEPS Technical Report for Mathematics: Scaling Results of Starting Cohort 1 for Four-Year Old Children. NEPS Survey Paper 45. Bamberg: Leibniz Institute for Educational Trajectories.

Pfeffer, Fabian T. 2018. “Growing Wealth Gaps in Education.” Demography 55 (3): 10331068. doi:10.1007/s13524-018-0666-7.

Pfeffer, Fabian T., and Martin Hällsten. 2012. Mobility Regimes and Parental Wealth: The United States, Germany, and Sweden in Comparison. SOEPpapers 500. Berlin: DIW. Reardon, Sean F. 2011. "The Widening Academic Achievement Gap Between the Rich and the Poor: New Evidence and Possible Explanations." In Whither Opportunity?: Rising Inequality, Schools, and Children's Life Chances, 91-116. Russell Sage Foundation.

Rothwell, David W., and Chang-Keun Han. 2010. "Exploring the Relationship Between Assets and Family Stress Among Low-Income Families.” Family Relations 59 (4): 396-407. doi:10.1111/j.1741-3729.2010.00611.x.

Schneider, Thorsten. 2004. "Der Einfluss des Einkommens der Eltern auf die Schulwahl [The Influence of Parental Income on School Choice]." Zeitschrift für Soziologie 33 (6): 471-492. doi:10.1515/zfsoz-2004-0602.

Schomaker, Michael, and Christian Heumann. 2018. "Bootstrap Inference When Using Multiple Imputation: Bootstrap Inference When Using Multiple Imputation.” Statistics in Medicine 37 (14): 2252-2266. doi:10.1002/sim.7654.

Schönberger, Katrin, and Tobias Koberg. 2017. Regional Data: Microm. Bamberg: Leibniz Insitute for Educatonal Trajectories.

Schulz, Wiebke, Reinhard Schunck, Martin Diewald, and Wendy Johnson. 2017. "Pathways of Intergenerational Transmission of Advantages During Adolescence: Social Background, Cognitive Ability, and Educational Attainment." Journal of Youth and Adolescence 46 (10): 2194-2214. doi:10.1007/s10964-017-0718-0.

Skopek, Jan, and Giampiero Passaretta. 2021. “Socioeconomic Inequality in Children's Achievement from Infancy to Adolescence: The Case of Germany." Social Forces 100 (1): 86-112. doi:10.1093/sf/soaa093.

Steen, Johan, Tom Loeys, Beatrijs Moerkerke, and Stijn Vansteelandt. 2017. "Flexible Mediation Analysis with Multiple Mediators.” American Journal of Epidemiology 186 (2): 184-193. doi:10.1093/aje/kwx051. 
Tibshirani, Robert. 1996. "Regression shrinkage and selection via the lasso." Journal of the Royal Statistical Society: Series B (Statistical Methodology) 58 (1): 267-288. doi:10.1111/j.2517-6161.1996.tb02080.x.

VanderWeele, Tyler J. 2015. Explanation in Causal Inference: Methods for Mediation and Interaction. New York, NY: Oxford University Press.

VanderWeele, Tyler J., Stijn Vansteelandt, and James M. Robins. 2014. "Effect Decomposition in the Presence of an Exposure-Induced Mediator-Outcome Confounder:" Epidemiology 25 (2): 300-306. doi:10.1097/EDE.0000000000000034. VanderWeele, Tyler J., and Stijn Vansteelandt. 2014. "Mediation Analysis with Multiple Mediators." Epidemiologic Methods 2 (1): 95-115. doi:10.1515/em-2012-0010.

Vansteelandt, Stijn, Maarten Bekaert, and Theis Lange. 2012. "Imputation Strategies for the Estimation of Natural Direct and Indirect Effects." Epidemiologic Methods 1 (1). doi:10.1515/2161-962X.1014.

Violato, Mara, Stavros Petrou, Ron Gray, and Maggie Redshaw. 2011. "Family Income and Child Cognitive and Behavioural Development in the United Kingdom: Does Money Matter?" Health Economics 20 (10): 1201-1225. doi:10.1002/hec.1665.

Walper, Sabine, and Mariana Grgic. 2013. "Verhaltens- und Kompetenzentwicklung im Kontext der Familie: Zur relativen Bedeutung von sozialer Herkunft, elterlicher Erziehung und Aktivitäten in der Familie [Development of behaviour and competence in the context of the family. The relative influence of parental upbringing and family activities]." Zeitschrift für Erziehungswissenschaft 16 (3): 503-531. doi:10.1007/s11618-013-0375-3.

Weinert, Sabine, Manja Attig, and Hans Günther Rossbach. 2017. "The Emergence of Social Disparities Evidence on Early MotherChild Interaction and Infant Development from the German National Educational Panel Study (NEPS).” In Childcare, Early Education and Social Inequality, 89-108. Edward Elgar Publishing. doi:10.4337/9781786432094.00014.

Weinert, Sabine, Anja Linberg, Manja Attig, Jan-David Freund, and Tobias Linberg. 2016. “Analyzing Early Child Development, Influential Conditions, and Future Impacts: Prospects of a German Newborn Cohort Study." International Journal of Child Care and Education Policy 10 (1). doi:10.1186/s40723-016-0022-6.

Wiborg, Øyvind N. 2017. "Family Wealth and School Grades in Norway - Exploring How the Immediate and Extended Family's Wealth Matter for the Children's School 
Performance.” In Social Inequality Across the Generations - the Role of Compensation and Multiplication in Resource Accumulation., edited by Jani Erola and Elina KilpiJakonen, 136-157. Cheltenham, U.K./Northampton, MA: Edward Elgar Publishing.

Williams Shanks, Trina R. 2007. "The Impacts of Household Wealth on Child Development." Journal of Poverty 11 (2): 93-116. doi:10.1300/J134v11n02_05.

Williams Shanks, Trina R., and Christine Robinson. 2013. “Assets, Economic Opportunity and Toxic Stress: A Framework for Understanding Child and Educational Outcomes." Economics of Education Review 33: 154-170. doi:10.1016/j.econedurev.2012.11.002.

Yeung, W Jean, and Dalton Conley. 2008. "Black-White Achievement Gap and Family Wealth.” Child Development 79 (2): 303-324. doi:10.1111/j.1467-8624.2007.01127.x.

Yeung, W. Jean, Miriam R. Linver, and Jeanne BrooksGunn. 2002. "How Money Matters for Young Children's Development: Parental Investment and Family Processes.” Child Development 73 (6): 1861-1879. doi:10.1111/1467-8624.t01-1-00511.

Zhan, Min, and Michael Sherraden. 2011. "Assets and Liabilities, Educational Expectations, and Children's College Degree Attainment." Children and Youth Services Review 33 (6): 846-854. doi:10.1016/j.childyouth.2010.12.006.

Zhou, Xiang. 2021. "Semiparametric estimation for causal mediation analysis with multiple causally ordered mediators.” Journal of the Royal Statistical Society: Series B (Statistical Methodology). doi:10.1111/rssb.12487.

Ziol-Guest, Kathleen M., and Claire C. McKenna. 2014. "Early Childhood Housing Instability and School Readiness." Child Development 85 (1): 103-113. doi:10.1111/cdev.12105. 


\section{Appendix}

\section{A. Descriptive Statistics}

\begin{tabular}{|c|c|c|c|}
\hline Variable & $\begin{array}{r}\text { Mean / } \\
\text { Median / } \\
\text { Proportion }\end{array}$ & Minimum & Maximum \\
\hline \multicolumn{4}{|l|}{ Household Net Worth } \\
\hline Mean & 310,997 & $-400 \mathrm{k}$ & $10 \mathrm{~m}$ \\
\hline Median & 50,000 & - & - \\
\hline Negative / 1. Quintile [-400k; 0) & $13.86 \%$ & - & - \\
\hline 2. Quintile $[0 ; 20 \mathrm{k})$ & $25.22 \%$ & - & - \\
\hline 3. Quintile [20k; 100k) & $19.80 \%$ & - & - \\
\hline 4. Quintile [100k; 210k) & $21.10 \%$ & - & - \\
\hline 5. Quintile [210k; 10m] & $20.02 \%$ & & \\
\hline \multicolumn{4}{|l|}{ Equivalized Household Income } \\
\hline Mean & 1,659 & 506 & 10,902 \\
\hline Median & 1,540 & - & - \\
\hline Income-poor / 1. Quintile [506; 980) & $15.90 \%$ & - & - \\
\hline 2. Quintile [980; 1389) & $24.38 \%$ & - & - \\
\hline 3. Quintile $[1,389 ; 1,694)$ & $19.62 \%$ & - & - \\
\hline 4. Quintile $[1,694 ; 2,111)$ & $19.79 \%$ & - & - \\
\hline 5. Quintile $[2,111 ; 10,902]$ & $20.32 \%$ & & \\
\hline \multicolumn{4}{|l|}{ Parents' highest ISCED } \\
\hline $0-3$ & $32.10 \%$ & - & - \\
\hline 4 & $7.68 \%$ & - & - \\
\hline $5 B$ & $19.25 \%$ & - & - \\
\hline $5 \mathrm{~A} / 6$ & $40.96 \%$ & - & - \\
\hline \multicolumn{4}{|l|}{ Parents' highest EGP } \\
\hline I & $37.00 \%$ & - & - \\
\hline II & $30.91 \%$ & - & - \\
\hline IIIa, IV & $12.62 \%$ & - & - \\
\hline IIIb, V, VI, VII & $19.47 \%$ & - & - \\
\hline At least one parent was born abroad & $26.57 \%$ & - & - \\
\hline Single parent & $6,06 \%$ & - & - \\
\hline Parents' average birthyear (Mean) & 1979 & 1958 & 1995.5 \\
\hline Child is a boy & $50.76 \%$ & - & - \\
\hline Child's month of birth (Mean) & $04 / 2012$ & $02 / 2012$ & $06 / 2012$ \\
\hline Number of older siblings (Mean) & 0.77 & 0 & 6 \\
\hline
\end{tabular}

Table A1. Descriptive Statistics

NEPS, starting cohort Newborns. $\mathrm{N}=2,377$. Weighted and averaged over 50 imputed datasets. 


\section{B. Indirect Effects}

\section{Joint Indirect}

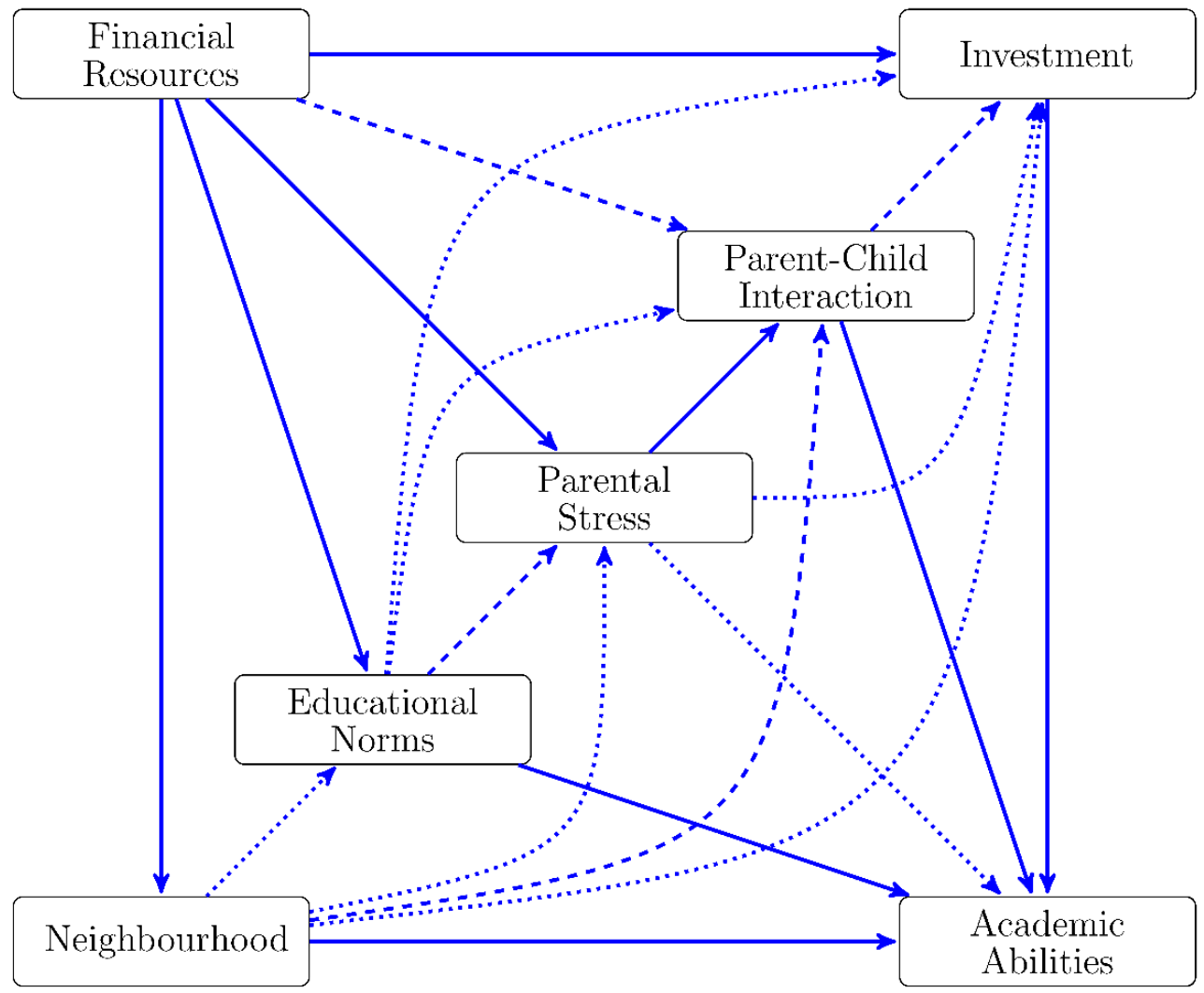

\section{NIE Neighbourhood}

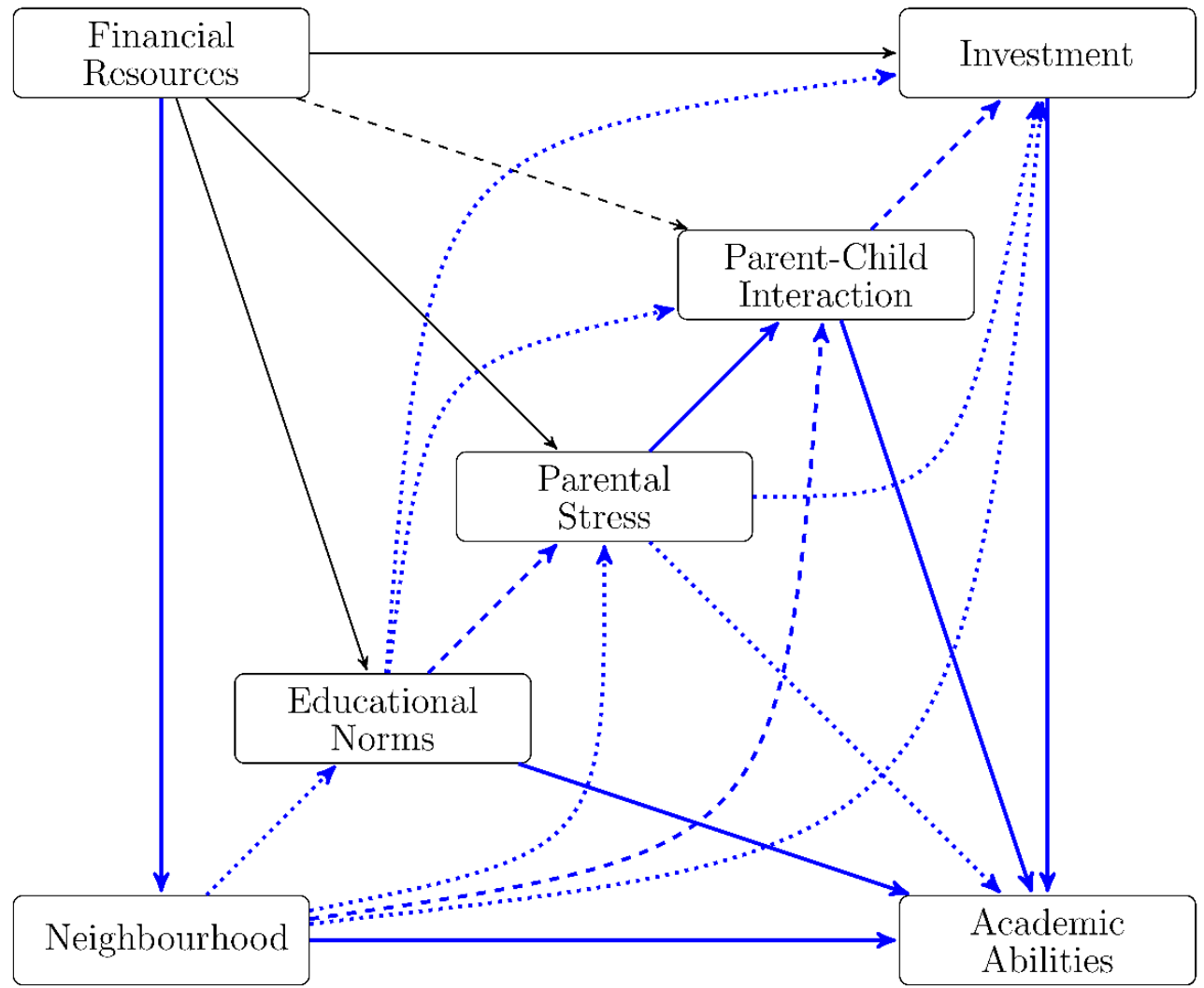


PIE Educational Norms and Aspirations

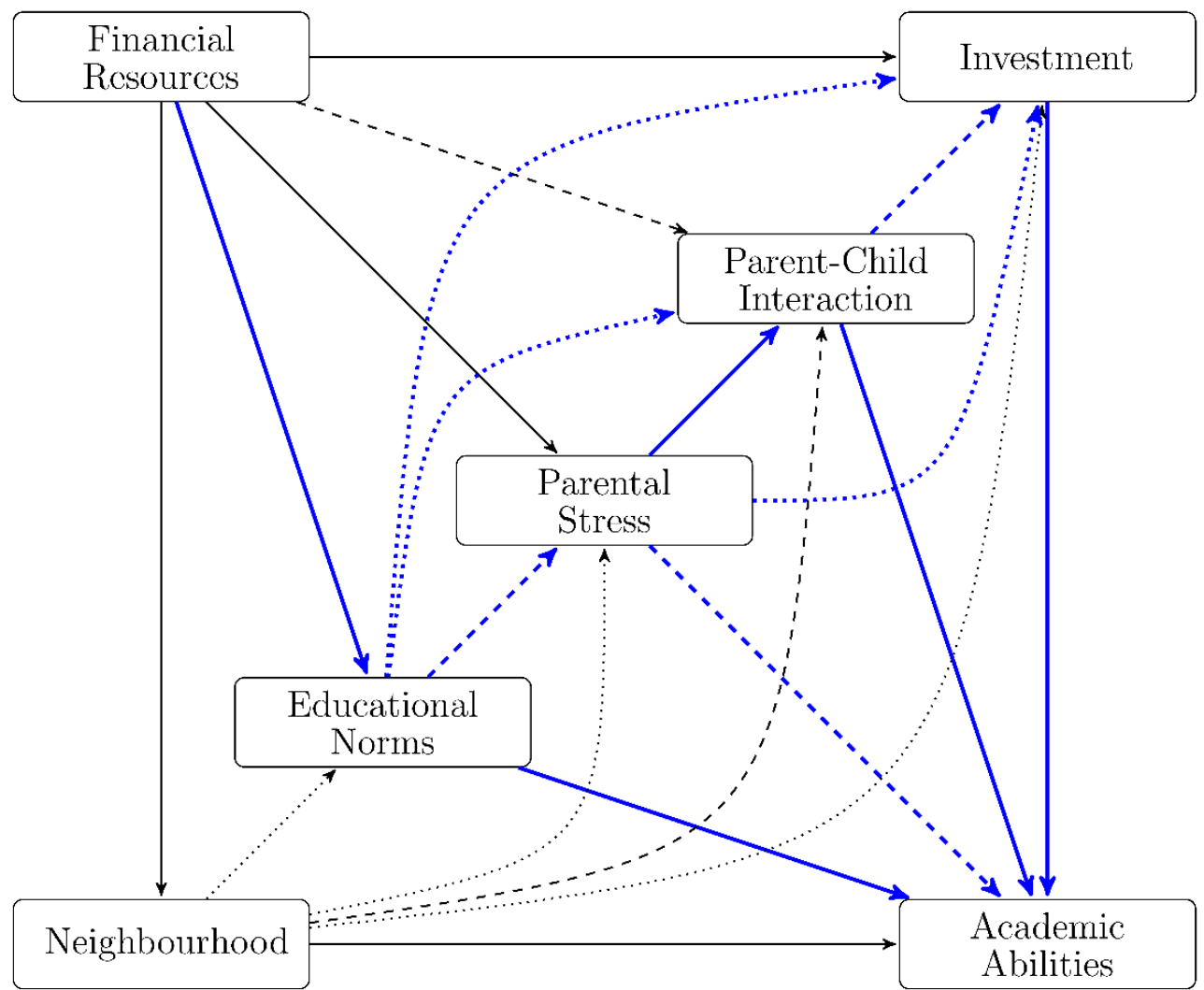

\section{PIE Stress}

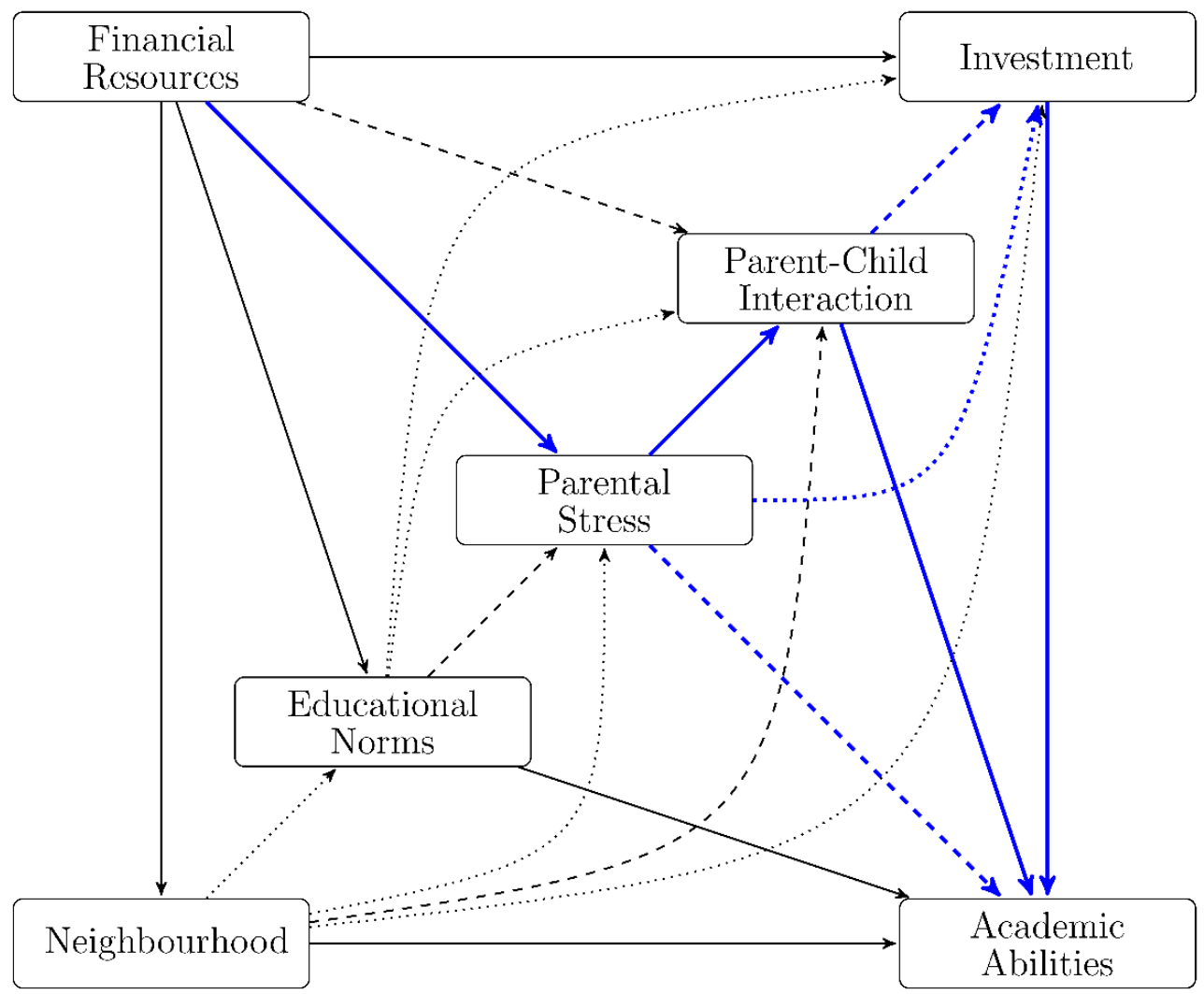


PIE Parent-Child Interaction Quality

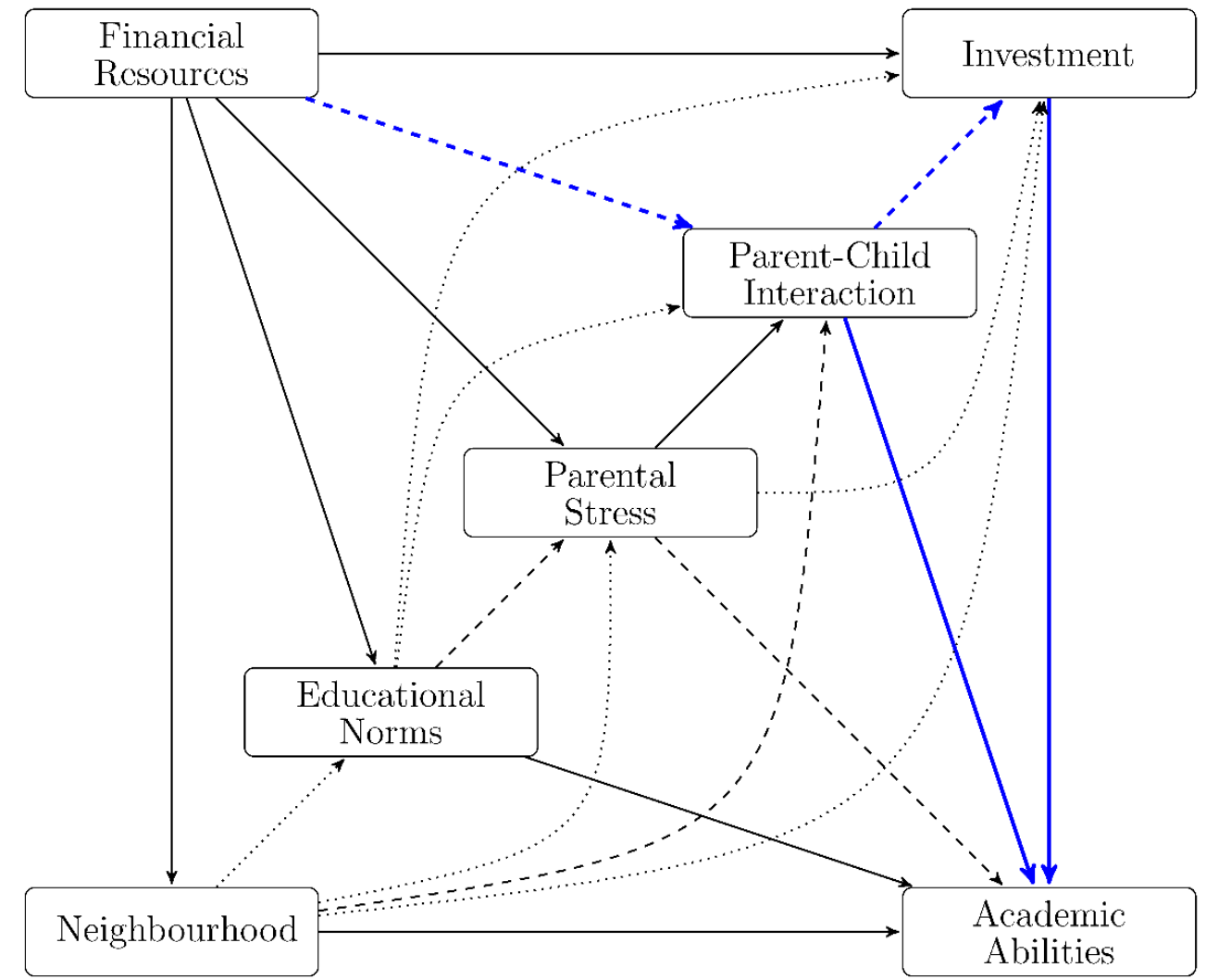

\section{PIE Investment}

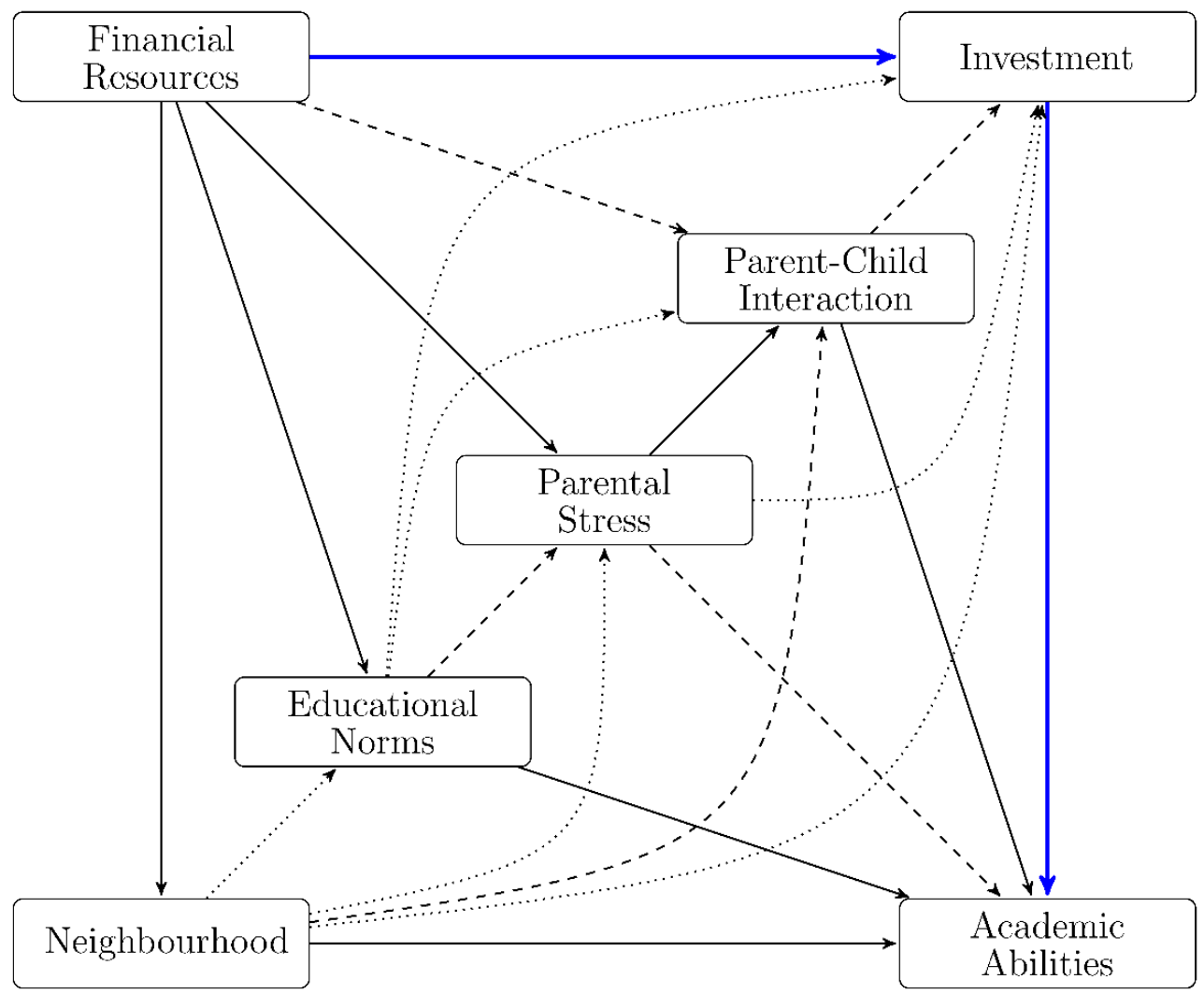


Figure B1. Paths captured by different indirect effects

Blue lines indicate pathways that are captured by the different indirect effect, black lines indicate pathways that are not captured. Dashed lines represent potential empirical effects that are, however, not considered theoretically. 


\section{Evaluating common support for financial resources and mediators}
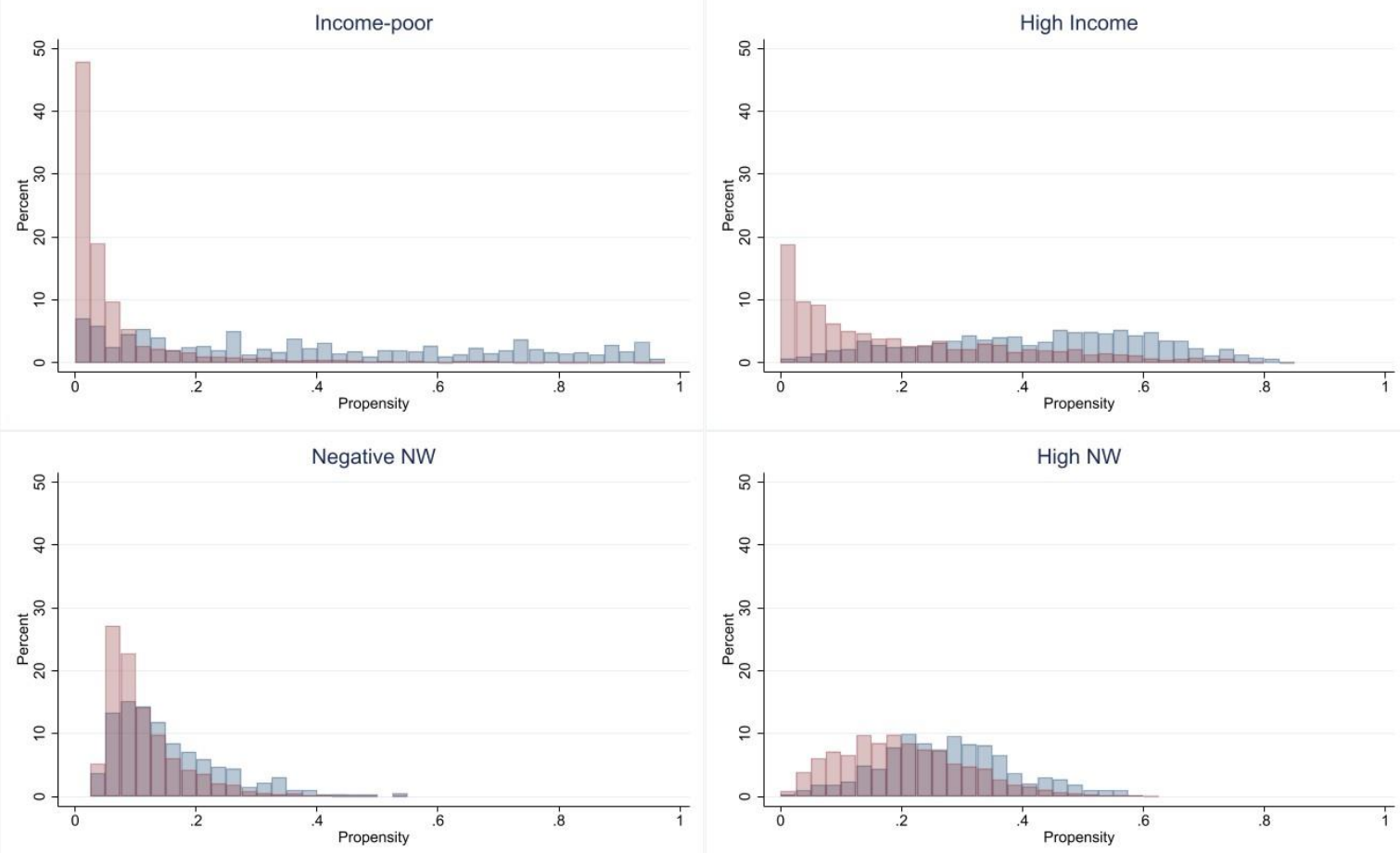

\section{Exposed \\ Not exposed}

Figure $\mathrm{C} 1$. Estimated propensities of being exposed to extreme income or net worth levels by observed exposure.

Propensities are estimated with logistic regressions of being exposed to extreme income or net worth levels on control variables and net worth or income. 

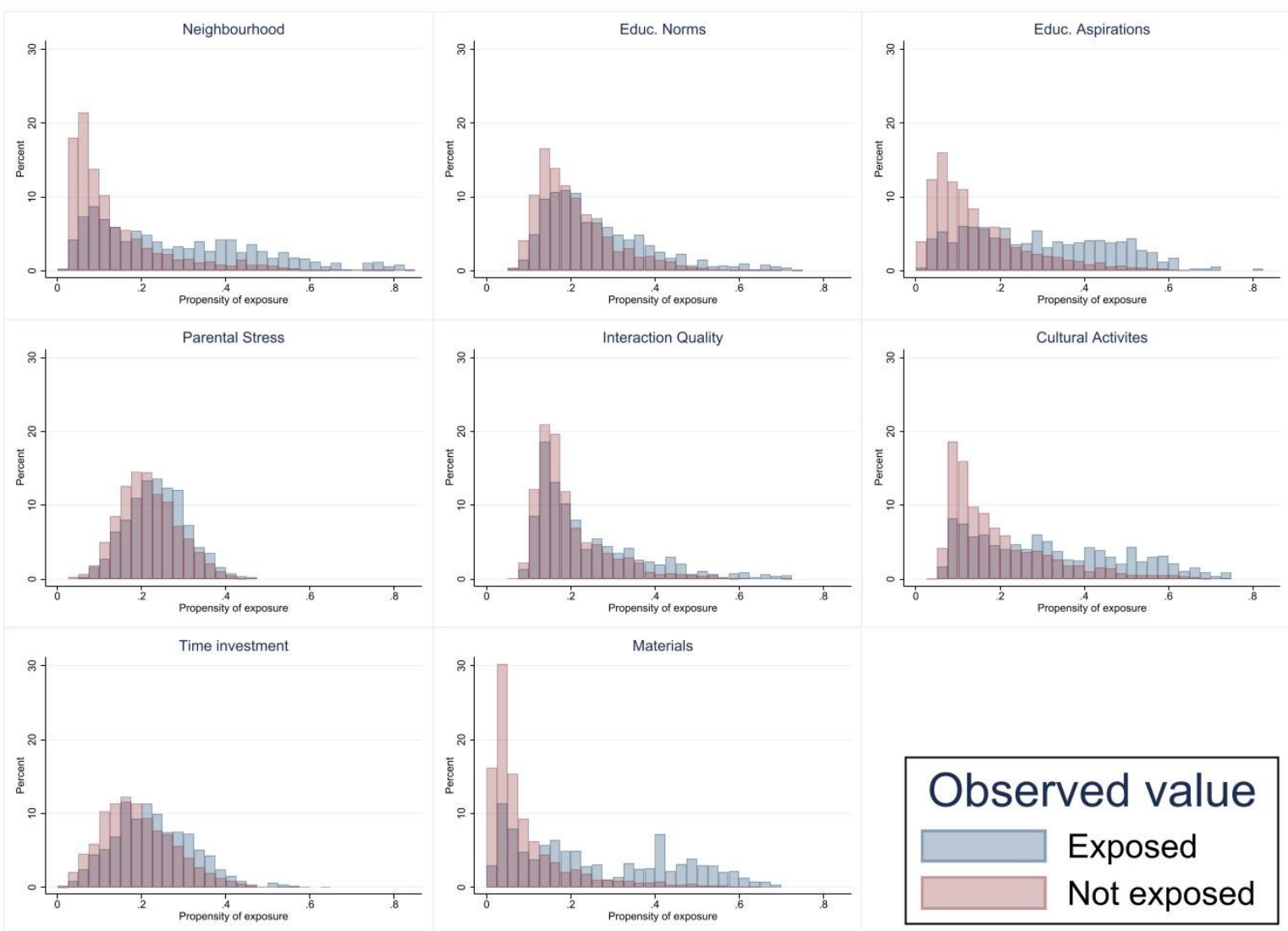

Figure C2. Estimated propensities of being exposed to the lowest quintile of the mediators by observed exposure.

Propensities are estimated with logistic regressions of being exposed to the lowest quintile of the mediators on parents' income, net worth, control variables, and all mediators earlier in the causal chain. 

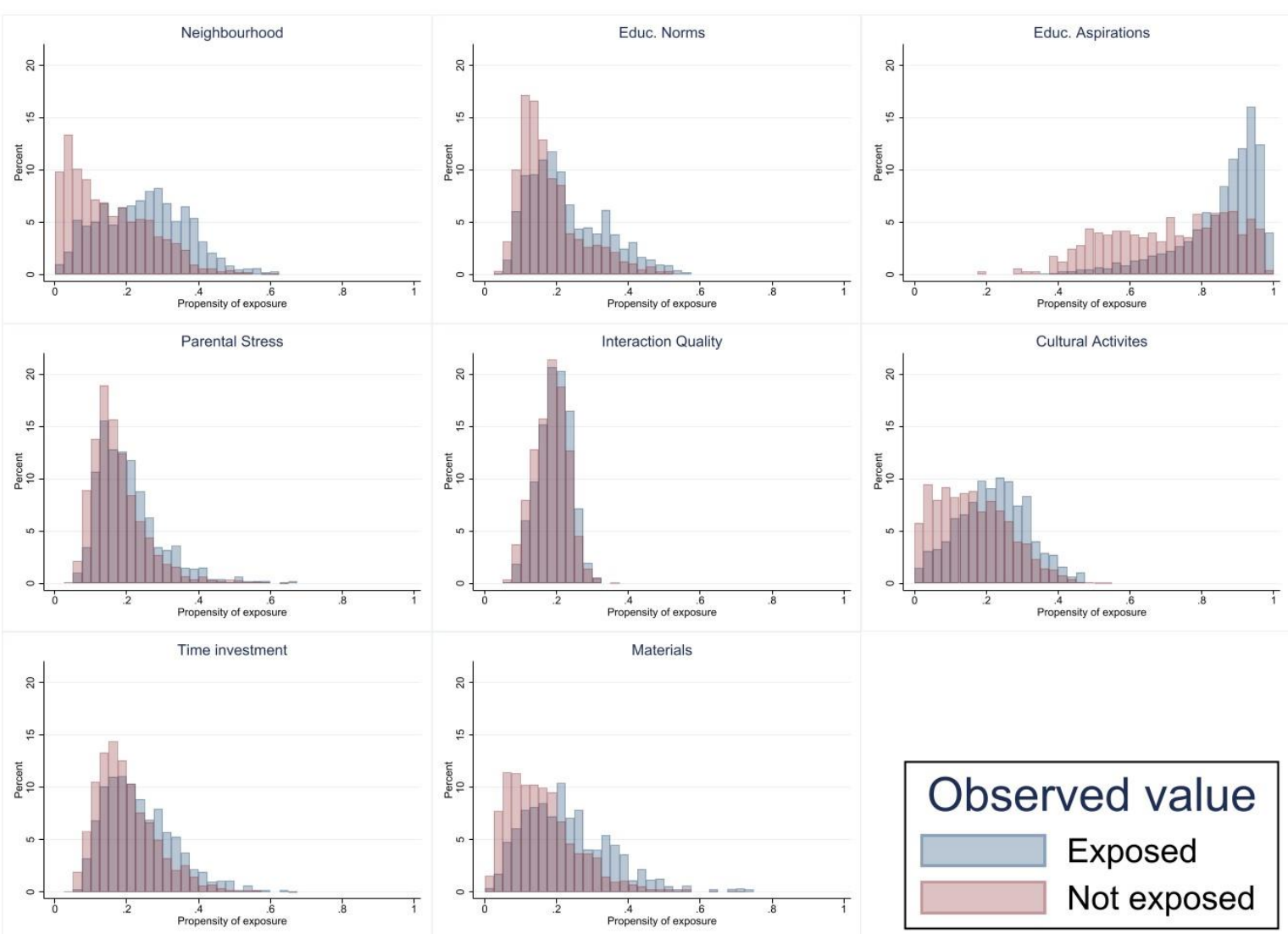

Figure C3. Estimated propensities of being exposed to the highest quintile of the mediators by observed exposure.

Propensities are estimated with logistic regressions of being exposed to the highest quintile of the mediators on parents' income, net worth, control variables, and all mediators earlier in the causal chain. 
D. Total differences without adjusting for control variables

\begin{tabular}{|c|c|c|c|c|}
\hline & Math (Age 4) & Math (Age 6) & Science & PPVT \\
\hline 2. Quintile & $\begin{array}{c}0.454 \\
{[0.204,0.704]}\end{array}$ & $\begin{array}{c}0.493 \\
{[0.245,0.741]}\end{array}$ & $\begin{array}{c}0.395 \\
{[0.160,0.631]}\end{array}$ & $\begin{array}{c}0.435 \\
{[0.193,0.676]}\end{array}$ \\
\hline 3. Quintile & $\begin{array}{c}0.424 \\
{[0.182,0.666]}\end{array}$ & $\begin{array}{c}0.524 \\
{[0.280,0.767]}\end{array}$ & $\begin{array}{c}0.515 \\
{[0.279,0.750]}\end{array}$ & $\begin{array}{c}0.664 \\
{[0.425,0.904]}\end{array}$ \\
\hline 4. Quintile & $\begin{array}{c}0.690 \\
{[0.453,0.928]}\end{array}$ & $\begin{array}{c}0.765 \\
{[0.505,1.026]}\end{array}$ & $\begin{array}{c}0.672 \\
{[0.432,0.913]}\end{array}$ & $\begin{array}{c}0.830 \\
{[0.595,1.064]}\end{array}$ \\
\hline 5. Quintile & $\begin{array}{c}0.800 \\
{[0.576,1.024]} \\
\end{array}$ & $\begin{array}{c}0.896 \\
{[0.657,1.134]} \\
\end{array}$ & $\begin{array}{c}0.700 \\
{[0.477,0.923]} \\
\end{array}$ & $\begin{array}{c}0.877 \\
{[0.647,1.107]} \\
\end{array}$ \\
\hline
\end{tabular}

Table D1. Difference in academic abilities by parental income without adjusting for control variables. Reference category: income-poor.

\begin{tabular}{lcccc}
\hline & Math (Age 4) & Math (Age 6) & Science & PPVT \\
\hline 2. Quintile & 0.194 & 0.149 & 0.139 & 0.064 \\
& {$[-0.040,0.428]$} & {$[-0.114,0.412]$} & {$[-0.099,0.376]$} & {$[-0.167,0.295]$} \\
3. Quintile & 0.396 & 0.426 & 0.331 & 0.280 \\
& {$[0.145,0.647]$} & {$[0.169,0.683]$} & {$[0.092,0.571]$} & {$[0.032,0.528]$} \\
4. Quintile & 0.459 & 0.499 & 0.415 & 0.398 \\
& {$[0.219,0.699]$} & {$[0.241,0.757]$} & {$[0.187,0.642]$} & {$[0.158,0.637]$} \\
5. Quintile & 0.413 & 0.440 & & 0.326 \\
& {$[0.175,0.652]$} & {$[0.187,0.694]$} & {$[0.090,0.561]$} & {$[0.169,0.661]$} \\
\hline
\end{tabular}

Table D2. Difference in academic abilities by parental net worth without adjusting for control variables. Reference category: negative net worth. 


\begin{tabular}{lcccc}
\hline & Math (Age 4) & Math (Age 6) & Science & PPVT \\
\hline 2. Quintile & 0.219 & 0.321 & 0.197 & 0.222 \\
& {$[-0.039,0.478]$} & {$[0.075,0.568]$} & {$[-0.044,0.438]$} & {$[-0.011,0.454]$} \\
3. Quintile & 0.062 & 0.165 & 0.181 & 0.267 \\
& {$[-0.202,0.327]$} & {$[-0.087,0.418]$} & {$[-0.082,0.444]$} & {$[0.018,0.516]$} \\
4. Quintile & 0.228 & 0.297 & 0.244 & 0.334 \\
& {$[-0.049,0.504]$} & {$[0.017,0.577]$} & {$[-0.020,0.508]$} & {$[0.071,0.597]$} \\
5. Quintile & 0.232 & 0.312 & 0.172 & 0.291 \\
& {$[-0.044,0.509]$} & {$[0.041,0.584]$} & {$[-0.098,0.441]$} & {$[0.025,0.557]$} \\
\hline
\end{tabular}

Table E1. Difference in academic abilities by parental income when adjusting for control variables but not for net worth. Reference category: income-poor.

\begin{tabular}{lcccc}
\hline & Math (Age 4) & Math (Age 6) & Science & PPVT \\
\hline 2. Quintile & 0.155 & 0.103 & 0.116 & 0.039 \\
& {$[-0.063,0.373]$} & {$[-0.135,0.341]$} & {$[-0.115,0.347]$} & {$[-0.175,0.254]$} \\
3. Quintile & 0.155 & 0.171 & 0.111 & -0.004 \\
& {$[-0.086,0.395]$} & {$[-0.068,0.409]$} & {$[-0.124,0.346]$} & {$[-0.234,0.226]$} \\
4. Quintile & 0.234 & 0.245 & 0.196 & 0.094 \\
& {$[-0.003,0.470]$} & {$[0.000,0.489]$} & {$[-0.034,0.426]$} & {$[-0.132,0.320]$} \\
5. Quintile & 0.131 & 0.147 & & 0.060 \\
& {$[-0.110,0.372]$} & {$[-0.103,0.396]$} & {$[-0.191,0.312]$} & {$[-0.176,0.307]$} \\
\hline
\end{tabular}

Table E2. Difference in academic abilities by parental net worth when adjusting for control variables but not for income. Reference category: negative net worth. 